\title{
Transforaminal Lumbar Epidural Steroid Injections
}

\author{
Laxmaiah Manchikanti, MD
}

Low back pain is an important medical, social, and economic problem involving approximately $15 \%$ to $39 \%$ of the population. Of the numerous therapeutic interventions available for treatment of chronic low back pain, including surgery, epidural administration of corticosteroids is one such intervention commonly used. Several approaches available to access the lumbar epidural space are the caudal, interlaminar, and transforaminal, also known as nerve root or selective epidural injection. The objective of an epidural steroid injection is to deliver corticosteroid close to the site of pathology, presumably onto an inflamed nerve root. This objective can be achieved by the transforaminal route rather than the caudal or interlaminar routes.
Reports of the effectiveness of epidural corticosteroids have varied from $18 \%$ to $90 \%$. However, reports of the effectiveness of transforaminal epidural steroids have shown it to be superior, with outcome data indicating cost effectiveness as well as safety.

This review describes various aspects of transforaminal epidural steroid injections in managing chronic low back pain.

KEYWORDS: Epidural steroid injections, caudal epidural, interlaminar epidural, transforaminal epidural, chronic low back pain, corticosteroids
Although epidural injections have enjoyed a long history of efficacy and safety in treating low back pain and lower extremity pain since 1901 (1), their use remains controversial. Throughout the $20^{\text {th }}$ century, the popularity of caudal, interlaminar, and transforaminal epidural injections has been waxing and waning as the most effective method in managing low back pain (2-12). Initially caudal epidural injections were popularized; with subsequent popularity of interlaminar epidurals, followed by the resurgence of caudal epidural injections; and, finally, the recent emergence of transforaminal epidural injections.

One of the major concerns about lumbar and caudal epidural steroids is that their true efficacy might not be evident in clinical trials because the injectate fails to reach the desired target (2). It has been postulated that even a well-performed lumbar or caudal epidural injection might fail to afford appropriate relief because the drug never reaches the required target in appropriate concentrations rather than the claim by opponents of epidural steroids that they do not work. Thus, emergence or resurgence of transforaminal epidural injections under fluoroscopy virtually

From Pain Management Center of Paducah, Paducah, Kentucky. Dr. Manchikanti is the medical director of Pain Management Center of Paducah. Address correspondence: Laxmaiah Manchikanti, M.D., 2831 Lone Oak Road, Paducah, Kentucky 42003. Email: drm@ apex.net guarantees the proper injection and delivery of medication to the target site. The object of this review is to focus on the various aspects of lumbar transforaminal epidural injections in the management of chronic low back pain.

\section{PROBLEM OF LOW BACK PAIN}

Low back pain is an important clinical, social, economic, and public health problem affecting the population indiscriminately. It is a disorder with no causal, few probable and many possible etiologies, occurring in many groups of the population, and with many definitions (13-29). There is astonishing agreement among professionals with regard to the enormity of chronic low back pain and its impact on society, even though the study of the epidemiology of low back pain is a murky field, and numerous modalities of therapeutic interventions available for treatment of chronic low back pain often spark debate among professionals (3, $4,8,10,13-30)$. In a recent prospective observational study, Fanuele et al (30) reported that the physical burden of patients with spine pain is often similar to or greater than that endured by patients with congestive heart failure, chronic obstructive pulmonary disease, cancer or orthopedic disorders. They concluded (30) that physical function status is significantly lower in patients with spinal disorders in the United States than in the general population, and that patients with spinal disorders have worse physical functional status scores than those with most other disease con- 
ditions. Comorbidities in patients with spinal disorders are associated with lower physical functional status (30). All types of treatments for back pain, including surgery and other interventional techniques have steadily increased, not only in frequency, but also in form, increasing the number of options during the past decade in all western countries, particularly the United States (2-13, 21-27, 31-40). With the increase in initial surgery, reoperations have also increased $(22,24-26,41,42)$. Reoperations generally tend to produce poorer results than initial back surgery $(22,24-$ $26,41,42)$.

Cassidy et al (43), assessing the 6-month prevalence of chronic low back pain and its impact on general health in the Canadian population, reported a lifetime prevalence of $84 \%$, with $13 \%$ grade III and grade IV pain and disability, which indicated high pain intensity and moderate -to-severe disability. This study reported that grade I low back pain was more common in the younger population, while older age groups reported a higher incidence of grade III, and IV levels of pain. Recurrent or chronic low back pain also has been reported to vary between $28 \%$ and $75 \%$, rather than $10 \%$ or under as it was originally thought (4449). The estimated average of age-related prevalence of persistent low back pain increased gradually from $12 \%$ in children and adolescents to $15 \%$ in adults and $27 \%$ in the elderly (29). Review of the epidemiology of low back pain and its risk factors showed no causal relationships. However, age and smoking were indentified as probable risk factors with all other factors being classified as either possible or unrelated (29).

\section{HISTORY}

Caudal epidural injection of drugs was introduced in 1901 by Cathelin, Pasquier and Leri, and Sicard (1, 50, 51). Cathelin (1) injected cocaine into the epidural space, whereas in 1925 Viner (52) administered epidural procaine, Ringer's solution, and saline. The advent of the interlaminar approach to the epidural space was considered at the time as a preferable route, as it is directed more closely to the assumed site of pathology than the caudal, thus facilitating the delivery of injectate directly to its target and requiring less volume $(2,3,12)$. However, subsequently, the disadvantages of the interlaminar approach, including extradural placement of the needle, which may go unrecognized without fluoroscopic guidance, and various other disadvantages and reports of the failure of interlaminar epidural steroids to provide statistically significant improvement, raised questions not only about interlaminar epidural administration of steroids but also about administration of corticosteroids in itself (2-12, 5358).

Transforaminal lumbar epidural injections have been emerging as an alternative to interlaminar and caudal epidural injections. Consideration of this procedure as new is by no means accurate. The earliest use of epidural steroids was by the transforaminal route $(59,60)$. In 1952 , Robecchi and Capra (59) administered periradicular injection of hydrocortisone into the first sacral nerve root and reported relief of lumbar and sciatic pain in a woman in the Italian literature. Lievre and colleagues (60) also reported transforaminal injection of steroids into the first sacral nerve root in the French literature. The sacral transforaminal epidural injection of steroids was popularized largely in the Italian literature $(59,61-66)$ and to a lesser extent in the French literature (60,67-69). There were no American reports until 1971, when Macnab described the diagnostic value of selective nerve root infiltration for radiculopathy (70). Since then, transforaminal epidural injections, also described as selective nerve root blocks, selective nerve root infiltration, or nerve root sleeve injections, have been widely used because they allow simultaneous morphologic and functional diagnosis of radiculopathy (71-77). During this time, clinical use of transforaminal epidurals in the management of low back and lower extremity pain was also initiated; and encouraging evidence has been emerging $(72,78-86)$.

\section{ANATOMY}

The spine is often divided anatomically into the anterior, neuraxial, and posterior compartments (87). The anterior compartment consists of the vertebral body and intervertebral disc, whereas the neuraxial compartment consists of structures within the epidural space and neural pathways, in contrast to the posterior compartment with facet joints and associated bony vertebral arch structures. Thus, epidural injections are used to diagnose and treat pain emanating from the anterior and neuraxial compartments. The neuraxial compartment includes all structures within the osseous and ligamentous boundaries of the spinal canal, including the posterior longitudinal ligament, ligamentum flavum, epidural, and epiradicular membranes.

Vertebral canal is a frequently used term by spinal injectionists. In the intact lumbar spine, the vertebral foramina of the five lumbar vertebrae are aligned to form a continuous channel, which is referred to as the vertebral canal (88). This vertebral canal anteriorly is formed by the posterior surfaces of the lumbar vertebrae, the inter- 
vening disks and the posterior longitudinal ligament; the posterior wall is formed by the laminae of the vertebrae and intervening ligamentum flava; and the lateral walls of the vertebral canal are formed by the pedicles of the lumbar vertebrae. The deficiency in the lateral walls between the pedicles where the superior and inferior vertebral notches oppose one another forms the intervertebral foramina (88). Thus, each intervertebral foramen is bounded anteriorly by an intervertebral disk, the adjacent lower third of the vertebral body above, and uppermost portion of the vertebral body below; posteriorly by vertebral lamina and a facet joint; and above and below by a pedicle (88).

Resting on the floor of the vertebral canal is the dural sac, which is posterior to the backs of the vertebral bodies and the intervertebral disks covered by the posterior longitudinal ligament; and, posteriorly, the dural sac is related to the roof of the vertebral canal, the laminae and ligamentum flavum (89).

The epidural space intervenes between the dural sac and the osseoligamentous boundaries of the vertebral canal. The epidural space is a potential space extending from the foramen magnum to the sacral hiatus and is located between the dura mater and the ligamentum flavum and periosteum of the surrounding vertebral arches. In adults, the spinal cord generally extends inferiorly to the L1 or L2 level. However, the surrounding dural sac extends inferiorly in the sacrum to approximately the $\mathrm{S} 2$ level within the bony sacral canal and then terminates at the sacral hiatus at the S4 or S5 level. The epidural space is compartmentalized into dorsal, and lateral, with subdivisions into anterior and posterior (90-92). The anterior epidural space is bordered by the posterior vertebral body, intervertebral disc, and posterior longitudinal ligament anteriorly, with the thecal sac posteriorly. The posterior epidural space borders against the thecal sac anteriorly and the ligamentum flavum and vertebral arches posteriorly. The ligamentum flavum is a rubbery, thick structure that serves as an important landmark, specifically with the blind interlaminar approach, and is located directly posterior to the epidural space. The dorsal sleeve accompanies each exiting nerve root. The spread of solution in both caudal and interlaminar injections thus is uncontrollable and fails to provide reliable segmental block due to inconsistent lateral flow into the ventral compartment, which varies with the tightness of the lateral recess and the size of the dural sac $(3,53$, 92). The width of the posterior epidural space beneath the neural arch at the midline varies throughout the length of the human spine from 1.5 to $2 \mathrm{~mm}$ in the upper cervical region to 5 to $6 \mathrm{~mm}$ at its greatest width in the mid lumbar spine and then gradually decreasing to $2 \mathrm{~mm}$ at the S1 level. However, the epidural space at all levels is triangular and widest in the midline underneath the junction of the lamina and narrows laterally beneath the facet joints.

The intervertebral foramina are formed superiorly and inferiorly by the pedicles of the adjacent vertebrae, anteriorly by the vertebral body and disc, and posteriorly by the facet joint capsule. The spinal nerve that exits through the neural foramen follows a variable course as the nerve root leaves the spinal canal, depending on the level of the spine (89). In the lumbar spine, the nerve roots travel inferiorly and exit in a lateral plane. Thus, the lumbar roots exit

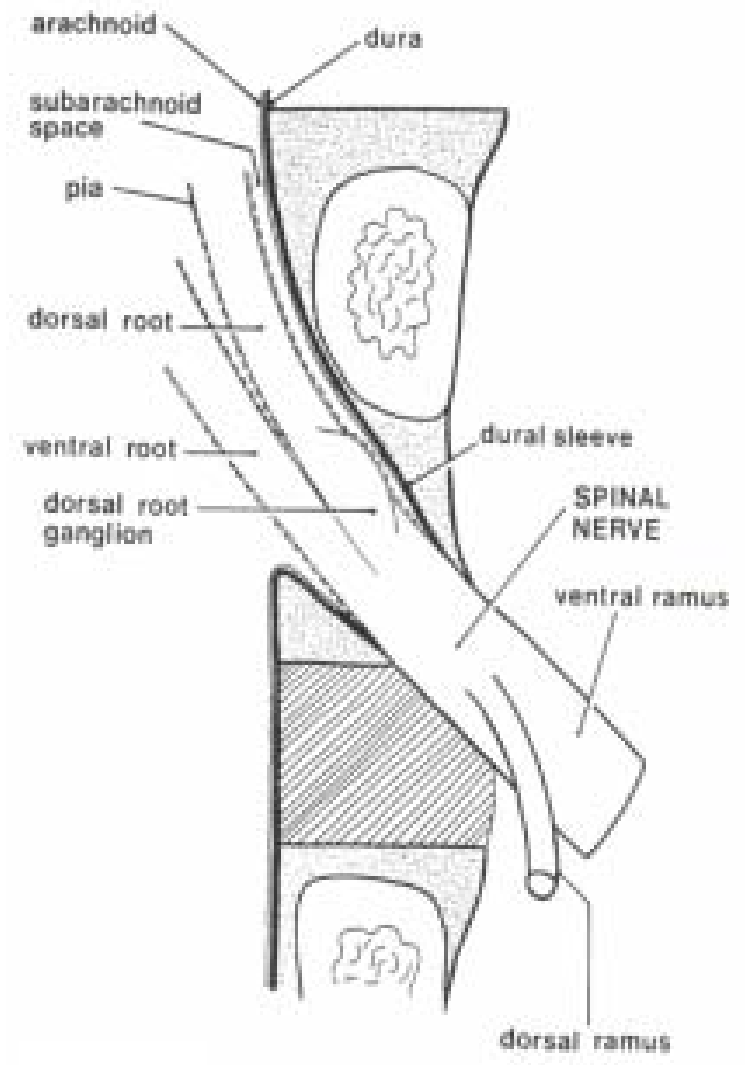

Fig. 1. A sketch of a lumbar spine nerve, its roots and meningeal coverings. The nerve roots are invested by pia mater, and covered by arachnoid and dura as far as the spinal nerve. The dura of the dural sac is prolonged around the roots as their dural sleeve, which blends with the epineurium of the spinal nerve. Reprinted from Bogduk (88) with permission. 
under the pedicle with a downward course of 40 to 50 degrees from horizontal and occupy the superior portion of each foramen (89). It is considered that the upper portion of the foramina just beneath the adjacent pedicle is as a safe zone to place the injectate close to the lumbar nerve root (Fig 1).

The sinuvertebral nerve originates lateral to the neural foramina and enters the spinal canal anterior to the dorsal root ganglion. It is a branch of the somatic ventral nerve root and the sympathetic grey ramus communicans. The sinuvertebral nerve innervates the outer annulus of the disc, posterior longitudinal ligament, epidural membranes, and dura at the segmental level and adjacent levels. Apart from these neural structures, the epidural space also contains veins, arteries, and adipose and loose areolar tissues. Each spinal nerve root is connected to the spinal cord by a dorsal and ventral root centrally. However, peripherally, each spinal nerve divides into a larger ventral ramus and a smaller dorsal ramus (89). The spinal nerve roots join the spinal nerve in the intervertebral foramen, and the ventral and dorsal rami are formed just outside the foramen. Consequently, the spinal nerves are quite short, as each one is no longer than the width of the intervertebral foramen in which it lies (89). The dorsal root of each spinal nerve transmits sensory fibers from the spinal nerve to the spinal cord, whereas the ventral root largely transmits motor fibers from the cord to the spinal nerve; however, it also transmits some sensory fibers (89). In addition, the ventral roots of L1 and L2 spinal nerves transmit preganglionic, sympathetic, efferent fibers. When spinal nerve roots leave the dural sac, they do so just above the level of each intervertebral foramen by penetrating the dural sac in an inferolateral direction, taking with them an extension of dura mater and arachnoid mater referred to as the dural sleeve (89). This sleeve encloses the nerve roots as far as the intervertebral foramen and spinal nerve, where the dura mater merges with, or becomes, the epineurium of the spinal nerve. The nerve roots are sheathed with pia mater embedded in spinal fluid (89). Further, immediately proximal to its junction with the spinal nerve, the dorsal root forms an enlargement, the dorsal root ganglion, which contains the cell bodies of sensory fibers in the dorsal root. Thus, the ganglion lies within the dural sleeve of the nerve root and occupies the upper, medial part of the intervertebral foramen but may lie further distally in the foramen if the spinal nerve is short (89). In addition, the angle at which each pair of nerve roots leave the dural sac varies, as the L1 and L2 root sleeve of the dural sac leave at an obtuse angle, but the dural sleeves of the lower nerve roots form increasingly acute angles with the lateral margins of the dural sac (89). Thus, the angles formed by the L1 and L2 roots are about 80 degrees and 70 degrees, whereas the angles of the L3 and L4 roots are each about 60 degrees, with the angle of the L5 root around 45 degrees (89). Similarly, the level of origin of the nerve root sleeves also varies from L1 downwards, with the L1 sleeve arising behind the L1 body, and the L2 sleeve arising behind the L2 body; but successive origin of the nerve root sleeves arises increasingly higher behind the vertebral bodies, until the sleeve of the L5 nerve root, which arises behind the L4/5 intervertebral disc (93).

The anatomy of the spinal nerve is of crucial importance to spinal injections. In summary, ventral and dorsal segmental roots join to form the segmental spinal nerve that traverses the neural foramen. However, outside the foramen, the spinal nerve divides into the dorsal and ventral rami.

\section{PATHOPHYSIOLOGY}

Tissues in the lower back capable of transmitting pain include the disk, nerve root, dura, muscle, ligament, fascia, and facet joint (94). Pain from lumbar disk herniation can arise from nerve root compression and stimulation of nociceptors in the anulus or posterior longitudinal ligament. The landmark description by Mixter and Barr in 1934 of intervertebral disk herniation led many practitioners to assume that intervertebral disk herniation is the most common cause of back problems (95). However, modern evidence implicates intervertebral disk herniation in only a small percentage of back complaints (96). Thus, a simple compression or mass effect cannot be the mechanism of pain due to disk disease (96). In fact, several studies evaluating the progress of disk herniation have shown that even though the resolution of symptoms tends to be associated with diminution of the size of the disk herniations, it is not always the case, as compression may continue in spite of the resolution of the symptomatology (97-100). In addition, it is also well known that disk herniations that are evident on computerized tomographic axial scan or on magnetic resonance imaging scan can be asymptomatic (101103). Various proposed mechanisms for radicular pain include partial axonal damage, neuroma formation, and focal demyelination (104); intraneural edema (105-108); and impaired microcirculation $(107,108)$. The other explanation surrounds the theory of chemical irritation and inflammation around the disks and nerve roots, which is considered a pain generator in conjunction with or without mechanical factors (109-131). The evidence for an inflammatory mechanism, though, continues to emerge and is convincing. This includes inflammatory properties of the 
nucleus pulposus demonstrated by sustained discharges in $\mathrm{A} \delta$ and $\mathrm{B} \beta$ fibers following application of nucleus pulposus to dorsal root ganglia (109-119). In addition, delayed nerve conduction velocity of nerve root is produced by placing the nucleus pulposus in the epidural space but without mechanical compression $(107,108)$; mechanical hyperalgesia follows placement of the nucleus pulposus in the epidural space, which correlates with phospholipase $\mathrm{A}_{2}$ (PLA2) immunoreactivity $(120,121)$; thermal hyperalgesia and mechanical hypoalgesia are produced by placing the anulus fibrosis and nucleus pulposus in the epidural space, which correlates with nitric oxide levels in the disk material $(120,121)$; blood flow is reduced in the dorsal root ganglion following application of the nucleus pulposus to the nerve root (131); endoneural fluid pressure in the dorsal root ganglion is increased by application of nucleus pulposus to the nerve root (131); and cultured disk material produces nitric oxide (122).

Even though inflammatory reactions between the nucleus pulposus and nerve roots have been suggested as playing an important role in disc herniation with sciatica, the pathogenic mechanisms linking herniated nucleus pulposus, nerve root injury, and sciatica are not completely known $(109,110,118,122-129)$. However, it is presumed that sensory neurons in the associated dorsal root ganglia are affected by this chemical injury (132). Lee et al (132) concluded that the behavioral pattern changes observed in the irritating nerve root model were caused in part by a high level of phospholipase A2 activity initiated by inflammation, and that the mechanism of action of epidural steroid injection in this model was inhibition of phospholipase A2 activity. Thus, investigations (132-135) provide clinical support for use of epidural steroid injections in managing chemical irritation and inflammation around the discs and nerve roots. In addition, it has been demonstrated experimentally that epidural application of the nucleus pulposus can induce pronounced morphologic and functional changes in the nerve roots (123). Intravenous methylprednisolone was shown to reduce the nerve root injury produced by placement of nucleus pulposus in the epidural space (133). Similarly, epidural injection of betamethasone in a model of lumbar radiculopathy showed a significant effect on thermal hyperalgesia (134). Minamide et al also (135) studied the effects of steroid and lipopolysaccharide on spontaneous resorption of herniated intervertebral disks in an experimental study in a rabbit and concluded that lipopolysaccharide accelerated the process of herniated intervertebral disk resorption, whereas high dose steroid suppressed the process.

\section{RATIONALE}

The objective of an epidural steroid injection is to deliver corticosteroid close to the site of pathology, presumably onto an inflamed nerve root. This is based on the premise that the corticosteroid delivered into the epidural space attains higher local concentrations over an inflamed nerve root and will be more effective than a steroid administered either orally or by intramuscular injection. In fact, the initial use of steroids in epidural injections was based on this premise $(2,59,60)$. Target site concentration of steroids depends upon multiple injection variables, though the main factor is the route of epidural administration. Caudal and interlaminar lumbar epidural injections are affected by the presence or absence of epidural ligaments or scarring, which may prevent migration of the posteriorly administered injectate to the anterior epidural space.

Even though caudal entry is relatively easily achieved, with minimal risk of inadvertent dural puncture, the caudal epidural injection necessitates injection of a substantial volume of fluid, thus diluting the specific injectate, namely corticosteroid $(2,53,136)$; and unrecognized placement of the needle either outside the epidural space or inside a blood vessel is seen in a substantial number of cases (53, 55, 136-141). Recently, epidural administration of steroids has been advised to be performed ideally under fluoroscopic guidance, which is considered to be the gold standard for accurate drug placement $(12,141,142)$. Extradural placement was shown to be present in $13 \%$ by Manchikanti and coworkers (136); in $9 \%$ by Stitz and Sommer (140); and in $38 \%$ by Renfrew and colleagues (137). Intravascular uptake during caudal epidural injections was reported to be $9 \%$ by Renfrew and colleagues (137), $6 \%$ by White and coworkers (53), $7 \%$ by Manchikanti et al (136) and $10.9 \%$ by Sullivan and colleagues (141). Similar to caudal epidural injections, interlaminar lumbar epidural injections have many disadvantages, even though the interlaminar route is often considered as a preferred route, as the entry is directed more closely to the assumed site of pathology, presumably facilitating delivery of the injectate directly to its target and requiring lesser volume than the caudal. With interlaminar entry of the lumbar epidural space, extradural placement of the needle may go unrecognized without fluoroscopic guidance (2, 12, 53-55); and erroneous placement of the needle by missing the targeted interspace by one or two levels without fluoroscopic guidance is possible $(55,56)$. In addition, preferential cranial flow of the solution in the epidural space probably necessitates the positioning of the needle a level below the site of suspected pathology, which may be difficult (56-58); 
Table 1. Disadvantages of caudal, lumbar, interlaminar and transforaminal epidural injections

\begin{tabular}{lll}
\hline Caudal & Interlaminar & Transforaminal \\
\hline $\begin{array}{l}\text { Requirement of substantial } \\
\text { volume of fluid }(2,53,136)\end{array}$ & Dilution of the injectate & Intravascular injection (141) \\
$\begin{array}{l}\text { Dilution of the injectate }(2, \\
\text { 53, 136) }\end{array}$ & Intravascular placement of the needle $(2,12,53-55)$ & Intraneural injection \\
$\begin{array}{l}\text { Extraepidural placement of } \\
\text { the needle }(53,55,136-141)\end{array}$ & Erroneous placement of needle $(55,56)$ & Neural trauma \\
$\begin{array}{l}\text { Intravascular placement of the } \\
\text { needle }(53,55,136-141)\end{array}$ & Difficult placement in postsurgical patients & Technical difficulty in presence \\
Atypical anatomy & Difficult placement below L4/5 interspace $(54)$ & of fusion and hardware \\
Subarachnoid puncture $(2,3$, & Deviation of needle to nondependent side (58) & \\
$12)$ & Subarachnoid puncture $(2,3,12)$ & \\
& Trauma to spinal cord $(143-145)$ &
\end{tabular}

difficulties may also be encountered with the placement of injectate below L5 for S1 nerve root involvement as well as potential deviation of the needle toward the nondependent side possibly being an issue $(54,58)$; the interlaminar epidural injection may be associated with trauma of the spinal cord specifically in the upper lumbar region (143-145); and potential risk of dural puncture and postlumbar puncture headache and total spinal block is a probability $(2,3,12)$. Table 1 illustrates various disadvantages of multiple routes of epidural administration of steroids.

Numerous reports of the effectiveness of epidural corticosteroids have varied in their response rate from $18 \%$ to $90 \%(2-12,90,146-165)$. However, the causes of this wide disparity in results have not been studied. The major cause of disparity proposed includes suboptimal placement or nonplacement of steroid close to the target site. Thus, wide fluctuations in the results of caudal and interlaminar epidural injections may be explained on the basis of inability to deliver the medication to the target site. Surprisingly, all controlled studies of interlaminar and caudal epidurals were performed without fluoroscopic guidance; whereas a few uncontrolled, open-ended clinical trials used fluoroscopy, ensuring the delivery of the medication at least into the epidural space if not to the target area. For optimum result, the corticosteroid should reach the ventral epidural space $(2,90)$. It is presumed that contrast medium, injected through either the caudal epidural or interlaminar epidural route, often fails to reach the ventral epidural space. Thus, the failure is secondary to inability of the drug to reach the target site in an appropriate concentration rather than a pharmaceutical and clinical failure of the corticosteroid. In fact, it was shown in normal volunteers that the transforaminal approach showed good ventral flow, whereas the interlaminar method showed predominantly dorsal flow, which was far removed from the usual site of inflammation (166). Saal and Saal (167) described various factors leading to the failure of epidural corticosteroid injections. These included: insurmountable pathology; inadequate delivery of corticosteroid to the target site; and noninjection factors, including inappropriate postblock activity, misinterpretation of pain generator, and unmasking phenomenon (Table 2). It appears that the major factor is the technical one involving the delivery of medication to the epidural space.

\section{CLINICAL EFFECTIVENESS}

Clinical trials of the efficacy of commonly used interventions in low back pain were reviewed by Koes and coworkers (168-170), which led to the conclusion that the methodological quality in these studies was disappointingly low. Clinical efficacy of any intervention is ideally mea- 
Table 2. Causes of failure of epidural steroid injections

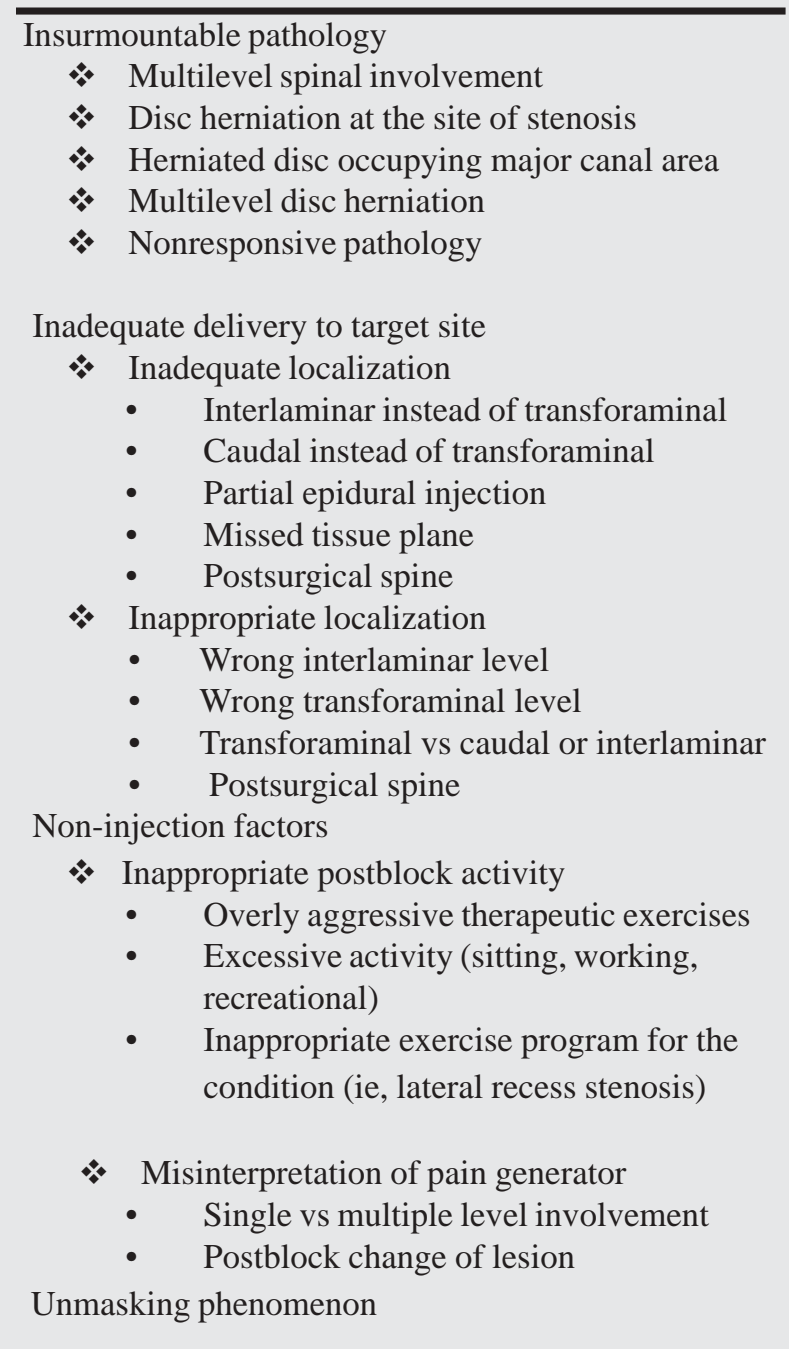

Source: Adapted and modified from Saal and Saal (167)

sured by randomized, double-blinded studies, which are considered to be the gold standard. However, issues of ethics, feasibility, cost and reliability pose challenges to the randomized trial (168-175). Most of the studies of epidural steroid injections have been performed by multiple specialty groups (rarely including pain specialists) and without radiographic control. Concato et al (176), analyzing five clinical topics with 99 reports that included both randomized studies as well as observational studies, showed that the well-designed observational studies (with either a cohort or a case control design) do not systematically overestimate the magnitude of the effects of treatments as com- pared with randomized, controlled trials on the same topic. Thus, this evaluation (176) essentially changed the current consensus about the hierarchy of study designs in clinical research. However, this is not to say that we do not need randomized, controlled studies. Pocock and Elbourne (177) observed that, in a systematic review of evidence on a therapeutic topic, one needs to take into account the quality of the evidence, as in any study, either a randomized or observational bias may exist either in design or analysis. Thus, one can say transforaminal epidural injections are in their clinical infancy in terms of their application as a traditional gold standard, as they have been subjected to only one double-blind, randomized trial. However, the prospective and retrospective observational evidence has been quite impressive thus far (Table 3), and may be considered without major reservation based on the systematic analysis of Concato et al (176) of well conducted observational studies in general.

Riew et al (86) in a prospective, randomized, controlled, double-blinded study evaluated the effectiveness of transforaminal epidural cortical steroids in subjects with disc herniations and/or spinal stenosis. The study included 55 patients with disc herniations or spinal stenosis referred for surgical evaluation. All subjects had clinical indications for surgery, and radiographic confirmation of nerve root compression. All had failed a minimum of 6 weeks of conservative care or had unrelenting pain. Exclusions included patients who had suffered trauma, patients with evidence of other serious diseases, patients demonstrating adverse reactions to the medications employed in the study,

Table 3. Results of effectiveness of published reports of transforaminal epidural steroid injections

\begin{tabular}{|c|c|c|c|}
\hline & $\begin{array}{l}\text { Study } \\
\text { Characteristics }\end{array}$ & $\begin{array}{l}\text { No. of } \\
\text { Patients }\end{array}$ & $\begin{array}{l}\text { Pain } \\
\text { Relief }\end{array}$ \\
\hline Reiw et al (86) & $\mathrm{DB}, \mathrm{RA}$ & 55 & $71 \%$ \\
\hline Lutz et al (83) & $\mathrm{P}$ & 69 & $75 \%$ \\
\hline $\begin{array}{l}\text { Weiner and } \\
\text { Fraser }(81)\end{array}$ & $\mathrm{R}$ & 28 & $61 \%$ \\
\hline $\begin{array}{l}\text { Kikuchi et al } \\
\text { (78) }\end{array}$ & $\mathrm{R}$ & 332 & $64 \%$ \\
\hline $\begin{array}{l}\text { Manchikanti et } \\
\text { al (79) }\end{array}$ & $\mathrm{R}, \mathrm{RA}$ & 225 & $60 \%$ \\
\hline Devulder (82) & $\mathrm{R}$ & 20 & $55 \%$ \\
\hline
\end{tabular}


and all patients with more than two levels of disease. Progress was monitored using the North American Spine Society Outcome questionnaire and an especially designed nerve root injection questionnaire. All subjects were assessed at baseline; at 2, 4, and 8 weeks postinjection; and again at 1 year. The primary outcome measure was whether patients underwent surgery or not, even though pain, disability, patient satisfaction, and treatment expectations were also evaluated. Both groups of patients had similar demographic and clinical characteristics. They were randomly allocated to receive an injection of a corticosteroid plus a local anesthetic, or the anesthetic alone, in a double-blinded manner. All patients received injections under fluoroscopy, up to four over the course of the study. All patients had the option of choosing surgery or participating in the study and all of the patients if requested received one or more additional injections, receiving the same injection to which they were randomized initially. Authors concluded that $71 \%$ of the patients studied with nerve root injections of corticosteroids avoided surgery, compared to $33 \%$ of controlled subjects. However, patients who opted not to have surgery showed greater improvement in terms of pain reduction, functional status improvement, and expectation of recovery than those who went on to have surgical intervention. The authors concluded that selective nerve root injections of corticosteroids were efficacious in helping otherwise excellent candidates for spine surgery to avoid an operation. They also speculated that selective nerve root injections might be effective because they provided more focal delivery of corticosteroids to the compressive nerves than other types of epidural injections. This study also showed that the first injection had the greatest impact on symptoms, with subsequent injections having less of an effect. The injections appear to provide benefit for patients with both acute and chronic complaints. However, it is also important to note that $33 \%$ of the patients in the local anesthetic injection group also avoided surgery.

Lutz et al (83) studied 69 patients in a prospective case series. They investigated the outcome of patients with lumbar herniated nucleus pulposus and radiculopathy using administration of fluoroscopic transforaminal epidural steroid injections. Patients were evaluated by an independent observer and were followed for an average period of 80 weeks, with a range of 28 to 144 weeks. Among the 69 patients, $75 \%$ of the patients had a successful long-term outcome, reporting at least a greater than $50 \%$ reduction between preinjection and post injection pain scores, as well as an ability to return to or near their previous levels of functioning after 1.8 injections per patient (range, one to four injections). They concluded that fluoroscopic trans- foraminal epidural steroids are an effective nonsurgical treatment option for patients with lumbar herniated nucleus pulposus and radiculopathy in whom more conservative treatments are not effective, and that they should be considered before surgical intervention.

Weiner and Fraser (81) treated 28 patients with severe radiculopathy secondary to foraminal or extraforaminal herniation of lumbar disks. In these patients, the disk herniation was proven by imaging studies and it failed to respond to rest and anti-inflammatory therapy, epidural injections, and physical therapy. The only remaining choice for these patients was surgical intervention due to the severity of pain and functional disability. The authors showed that 22 of the 28 patients improved dramatically, with sustained relief lasting an average of 3.4 years, with a range of 1 to 10 years. Further analysis showed that, of the 28 patients, three obtained no relief and subsequently underwent diskectomy; but three obtained immediate relief and relapsed within 6 months, whereas one patient obtained minimal relief but was able to tolerate continuing symptoms; and seven patients received moderate relief that allowed them to return to most activities but with caution and occasional symptomatic treatment. Fourteen of the 28 patients had complete relief of their pain, sustained for periods of follow-up that ranged from 1 to 10 years.

Kikuchi et al (78) studied the therapeutic effect of transforaminal nerve root injections in 332 patients. They reported that this procedure not only had therapeutic effect but also had great diagnostic value in functional as well as morphological aspects. They reported that 22 of 45 nonoperated cases of disk ruptures, 30 of 39 patients with spondylosis, and five of six patients with degenerative spondylolisthesis all experienced more than 6 months of pain relief and thus were able to avoid surgical intervention. Furthermore, they reported that over the long term, relief was seen in $64 \%$ of these patients.

Manchikanti et al (79) compared the three routes of epidural steroid injections in the management of chronic low back pain. This retrospective evaluation included 225 patients and was randomly derived from a total sample of 624 patients suffering with low back pain from a total of 972 patients referred to the center for pain management. The evaluation was performed by an independent evaluator. The study design included three groups: Group I, which received interlaminar epidurals with a midline approach in the lateral position, with entry between L3/4 or L4/5 in nonsurgical patients and above the scar either at L2/3 or L1/2 in postsurgical patients, using a loss-of-resistance 
technique; Group II, which received caudal epidurals, the procedures being performed in prone position, under fluoroscopy with confirmation of the position by injection of contrast; and Group III, which received transforaminal epidural corticosteroid injections, using either sacral or lumbar transforaminal technique under fluoroscopy. The results of the study showed that all three routes of administration of epidural corticosteroid administration were clinically effective, though administration by caudal and transforaminal routes was more successful in obtaining longer term relief. Further, this study also showed that the transforaminal injections were the ideal, as the most significant improvement was noted with the least expense compared to the caudal epidural, and to interlaminar epidural without the use of fluoroscopy. This study showed significant relief (which was defined as greater than 50\% relief) per procedure for all patients in the study with 3.45 +0.17 weeks, $6.06+1.27$ weeks, and $7.69+1.20$ weeks duration for blind intralaminar epidural, fluoroscopically directed caudal and transforaminal epidural injections. Comparison of clinical effectiveness of pain relief of blind interlaminar, fluoroscopically directed caudal and transforaminal epidural injections is shown in Fig 2.

Devulder (82) also studied transforaminal epidural injections, which he termed nerve root sleeve injections with corticosteroids; however, they were combination with hyaluronidase. In a study of 20 patients with persistent pain after surgery, ranging from 1 to 9 years in duration and diagnosed as failed back surgery syndrome, Devulder (82) reported that $55 \%$ of the patients reported greater than $50 \%$ relief at 1 month, while $50 \%$ of the patients experienced continued relief after 3 months.

Transforaminal injections have also been evaluated for their prognostic value. Derby and colleagues (80) correlated surgical outcome with pain relief following transforaminal epidural injections with local anesthetic and steroids and reported that patients who fail to obtain sustained relief of radicular pain following the block were less likely to benefit from subsequent surgical intervention.

\section{OUTCOMES AND COST EFFECTIVENESS}

Outcomes may be assessed by evaluation of the quality of life, which is also known as functional status, health status, health-related quality of life; well-being of the patient, satisfaction with care, health-services utilization/economic analysis, and medical findings $(3,12,79,178-187)$. The quality-of-life assessment is designed to evaluate the patient's abilities to function in his or her own world. Physical functioning measures the ability to perform physical activities such as walking, climbing stairs, or carrying things. Evaluation focuses on the patient's major interests of functional impairments, improvement in areas such as playing with children/grandchildren, having sexual relations, returning to work, going to school, homemaking or performing other activities of daily living. Quality of life also measures social functioning, which determines
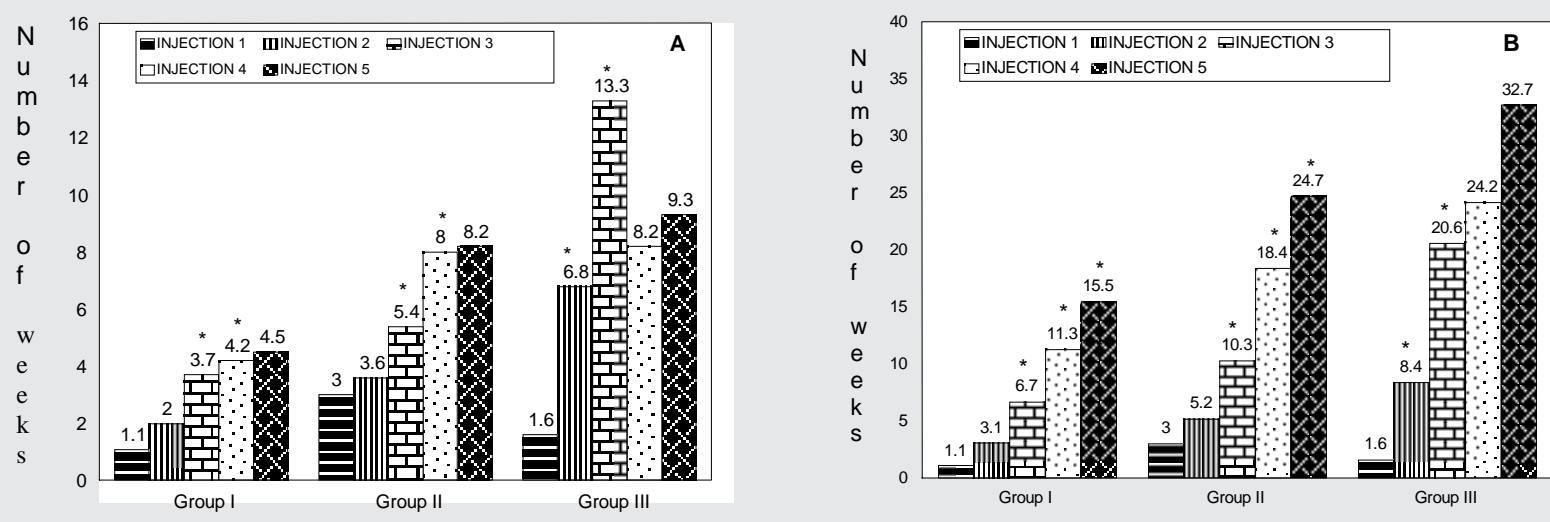

Fig 2. Comparison of clinical effectiveness of pain relief of blind interlaminar, fluoroscopically directed caudal and transforaminal epidural injections

A. Comparison of effectiveness of multiple injections on duration of significant pain relief $(>50 \%)$ in three groups

B. Comparison of cumulative effectiveness of multiple injections on duration of significant pain relief $(>50 \%)$ in three groups

* Indicates significant difference

Adapted and modified from Manchikanti et al (179) 
whether health problems affect normal social activities, such as seeing friends or participating in group activities.

In the arena of cost effectiveness and outcomes, it was shown that a simple reduction of diastolic blood pressure from 110 to $90 \mathrm{mmHg}$ was achieved at a cost of $\$ 16,330$ for a 60-year-old man in 1974 (180). Costs of inpatient chronic pain programs range as high as $\$ 17,225$, and the costs of outpatient treatment programs range from $\$ 7,000$ to $\$ 10,000$ (179). In addition, chronic pain patients may incur health-care bills in excess of $\$ 20,000$ annually for repetitive and, in some cases, redundant diagnostic workups, physical therapy, psychological interventions, and drugs. The costs of back pain are enormous. Guo and colleagues (188) estimated that back pain accounted for 150 million lost workdays in the United States every year, with $\$ 14$ billion in wage costs alone. They (188) essentially demonstrated the monumental effect of the pain problem and that even a $1 \%$ reduction in overall prevalence could considerably reduce the morbidity of low back pain, saving society billions of dollars. In calculation of the cost effectiveness of lumbar diskectomy for the treatment of herniated intervertebral disk, it was concluded that, for carefully selected patients with herniated disks, surgical diskectomy with a cost-effective treatment at a discounted cost of $\$ 12,000$ per diskectomy is $\$ 29,000$ per life year adjusted for quality (189). In other studies going a step further that considered the chronic nature of pain in patients when initial surgical treatment for herniated disk fails, it was shown that success of a second operation was $50 \%$, with an additional $20 \%$ considering themselves worse after the surgery; whereas with a third procedure, the success rate was only $30 \%$, with $25 \%$ considering themselves worse; and, after four operations, the success rate dropped to $20 \%$, with an enormous increase of worsening of these patients to $45 \%$ (24). Thus, if the additional costs of repeat surgery are taken into consideration, the cost of lumbar surgery would be much higher. Evaluation of the cost effectiveness of intrathecal therapy for pain secondary to failed back surgery syndrome, comparing ordinary therapies for achieving a defined outcome, showed the cost of medical management to be $\$ 85,186$ per 5 years, $\$ 17,037$ per year, and $\$ 1420$ per month (190). This evaluation (190) also showed that intrathecal morphine delivery resulted in a lower cumulative 60 -month cost of $\$ 82,893$ per 5 years, $\$ 16,579$ per year, and $\$ 1382$ per month.

Evaluation of the cost effectiveness of epidural injections including transforaminal steroid injections for the management of chronic low back pain revealed surprising results, with cost effectiveness of caudal epidural steroids at \$3635 and transforaminal steroids at \$2927 per year, with blind

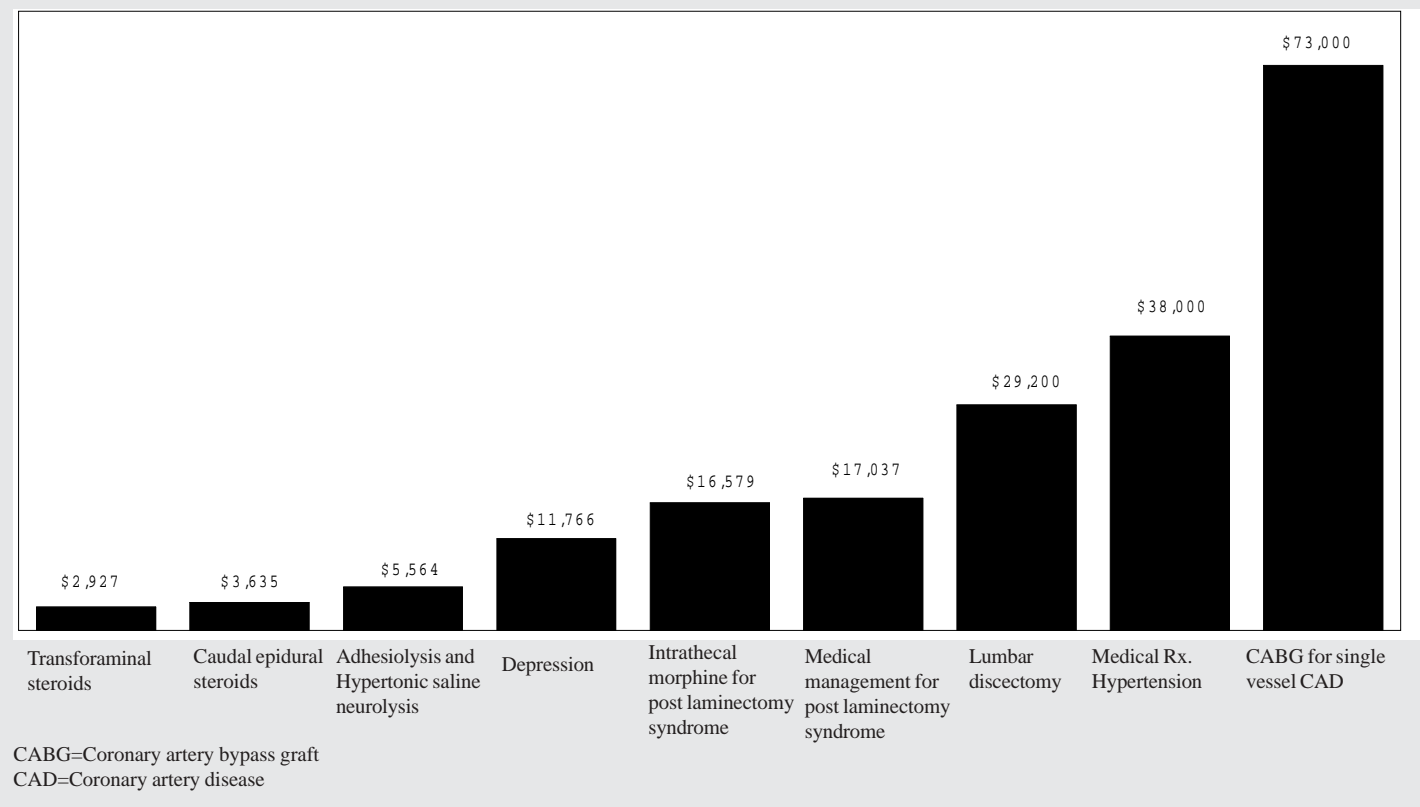

Fig. 3. Cost effectiveness of various types of therapy in managing medical conditions including chronic low back pain Reprinted and modified from Manchikanti et al (12) with permission 
interlaminar lumbar epidural steroids at $\$ 6024$ per year (79).

The transforaminal epidurals appear to be clinically effective with a favorable outcome and cost effectiveness, compared not only to blind interlaminar epidural steroid injections and fluoroscopically directed caudal epidural steroid injections but also to numerous other modalities of treatment (Fig. 3).

\section{COMPLICATIONS}

The most common and worrisome complications of transforaminal epidural steroid injections in the lumbar spine are related to dural puncture, infection, and steroids (191194). In a large survey of reports of adverse reactions associated with epidural steroid injections. Abram and O'Connor (191) reported two cases of epidural abscess, and two cases of meningitis. No such reviews exist for transforaminal epidural steroid injections.

Manchikanti et al (79) noted: no incidence of infection; $10 \%$ incidence of rash and itching; $4 \%$ incidence of weight gain; and no incidence of subarachnoid puncture arachnoiditis, paralysis, weakness, bladder disturbances, or other complications following transforaminal epidural steroid injections. Side effects related to the administration of steroids are generally attributed to the chemistry or pharmacology of the steroids and are similar by any route of administration. However as reported by Manchikanti et al (79), steroid-related complications are expected to be much fewer with transforaminal epidural steroid injections due to focused delivery of medication to the target site, requiring a lesser volume of steroid. Manchikanti et al (195) also reported no significant weight gain or low bone mass density in patients receiving neuraxial steroids monitored for 1 year in a controlled, prospective evaluation. Various complications related to steroid administration in neural blockade are well described (2, 3, 12, 193-195). The only complication that may be theoretically more prevalent with transforaminal epidural injections is trauma to the nerve root even, though it has not yet been reported.

\section{INDICATIONS}

Indications for transforaminal epidural injections include various diagnostic dilemmas, localized neural irritation, discogenic pain and postsurgical syndromes. Numerous investigators in the past have attempted to identify appropriate indications for blind interlaminar and caudal epidural steroid injections, with disappointing correlations and results $(3,164,196,197)$. Indications for diagnostic transforaminal injections stem from the fact that clinical features and imaging or neurophysiologic studies do not permit the accurate diagnosis of the causation of spinal pain in the majority of patients in the absence of disk herniation and neurological deficit $(3,12,198-214)$. Further, transforaminal epidural injections are also indicated based on recurring figures showing the overall rate of inaccurate or incomplete diagnosis in patients referred to pain treatment centers as ranging from $40 \%$ to $67 \%$, the incidence of psychogenic pain to be only one in 3000 patients, and the presence of organic origin of pain in $98 \%$ of cases of those mistakenly branded as psychosomatic cases $(215,216)$. In addition, biopsychosocial issues such as somatization disorder, inappropriate symptoms and signs, which are asserted to prove that there is nothing wrong with the patient, with claims that either the patient is exaggerating or malingering have been questioned (217-221). Finally, the most compelling reason is that chronic low back pain is a diagnostic dilemma in $85 \%$ of patients, even in experienced hands with all of the available technology $(3,12,203)$. Thus, utilizing a diagnostic algorithm that incorporates transforaminal epidural injections, diagnostic abilities can be improved in patients in whom there is a lack of definite, diagnostic, radiologic or electrophysiologic criteria.

Similarly, transforaminal epidural injections are indicated as a therapeutic intervention based upon a multitude of considerations including; the fact that the common source of chronic spinal pain involving the neuraxial compartment is accessible to transforaminal epidural injections; removal or even correction of structural abnormalities of the spine may fail to cure and may even worsen painful conditions; degenerative processes of the spine and the origin of spinal pain are extremely complex; and the effectiveness of a large variety of therapeutic interventions in managing chronic low back pain has not been demonstrated conclusively $(3,8,9,12)$. Further, Wallis and colleagues (221) showed that pain relief achieved following radiofrequency facet denervation not only returned these patients to work but also resolved all of the psychological problems, questioning the extraordinary focus and inordinate importance given to the patients' psychological status and dispelling the myths about psychological involvement in chronic pain. The indications and evidence in favor of therapeutic transforaminal epidural steroids in managing chronic low back pain are balanced and less controversial than diagnostic blocks and other means of administration of epidural corticosteroids, namely, blind interlaminar epidural injections $(2,3,12,78-86,91)$. 


\section{TECHNIQUE}

Lumbosacral transforaminal epidural injections are always performed under fluoroscopy. The technique of transforaminal epidural injection was developed by Tajima and colleagues (72). Subsequently, Derby and coworkers (222) described the transforaminal epidural injection in detail.

The procedure is performed commonly with the patient in the prone position, using fluoroscopy to identify the essential bony landmarks. The oblique or posterior approach may be used with either a single - or double-needle technique, with the patient in prone, lateral or semi-lateral position. The author prefers a single-needle posterior approach in the prone position. The target landmark for transforaminal needle placement is the inferior aspect of the pedicle, with the needle placement just below superior to the existing nerve root in the 6 o'clock position. Bogduk (89) and Derby and coworkers (222) described a safe "triangle" at this location, with three sides corresponding to the horizontal base of the pedicle, the outer vertical border of the intervertebral foramen, and the connecting diagonal nerve root and dorsal ganglion (Fig. 1). Thus, a needle placed into the safe triangle will lie above and lateral to the nerve root.

For the posterior approach, the patient is in the prone position and the fluoroscopy unit is positioned with the spinous process in the center of the spine. The needle is inserted into the skin over the lateral border of and approximately halfway between the two adjacent transverse processes at the target interspace. The needle is advanced toward the lower edge of the transverse process, near its junction with the superior articular process. The needle may be directed towards the edge of the transverse process, at which time the needle may be retracted slightly and redirected toward the base of the appropriate pedicle and advanced very slowly to the final position. However, the needle may also be directed towards the pedicle without this intermediate step. Following this, a small volume of contrast is injected and the pattern of dispersion into the nerve root is noted. If the needle has penetrated the epiradicular membrane surrounding the nerve root, an appropriate and positive image of the nerve root will be seen on fluoroscopy, with appropriate dispersion of the contrast as shown in Fig. 4. However, the needle tip may be repositioned several millimeters inferior to the pedicle sometimes to appropriately position the needle into the epiradicular membrane. A classic contrast pattern with a dispersion showing a neurogram is not always achieved. The contrast filling may sometimes reveal pathology in the area of the exiting nerve root such as an abnormal position and course of the nerve secondary to a compressive vertebral osteophyte or lateral disk herniation (222). After a satisfactory contrast dispersion pattern is observed, a mixture of local anesthetic and corticosteroid is injected.

The transforaminal approach for the S1 nerve root also includes a single-needle technique. Once again, the patient is in the prone position, and the $\mathrm{S} 1$ foramen is visualized under fluoroscopy and appears as a small radiolucent circle just below the oval $\mathrm{S} 1$ pedicle. It may be necessary to direct the fluoroscopic beam in a cephalocaudad direction for the alignment of anterior and posterior foramina.

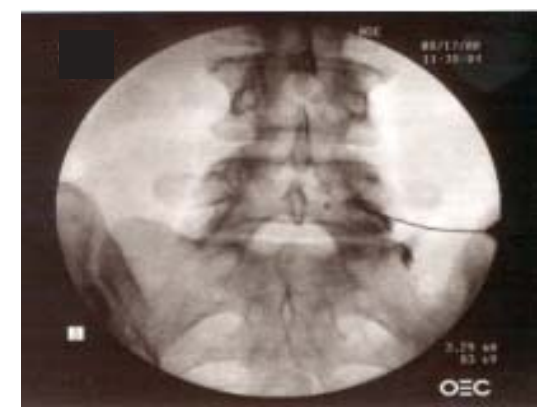

A. Single-needle positioning in posterior approach

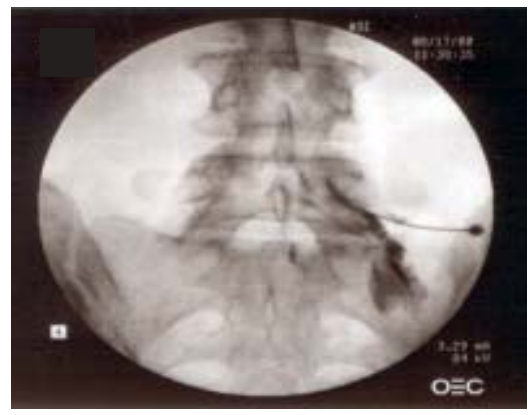

B. Contrast injection demonstrating dispersion of contrast into nerve root caudally and to epidural space cephalad

\section{Fig. 4. Transforaminal administration of epidural injection at L5 in prone position with posterior approach}


The needle is inserted slightly lateral and inferior to the S1 pedicle and advanced slowly through the posterior foramina to the medial edge of the pedicle. However, extreme caution must be exercised to avoid advancing the needle through both the posterior and anterior S1 foramina and into the pelvis. Thus, first contacting the posterior sacral bone prior to entering the $\mathrm{S} 1$ foramina provides the depth and direction of the needle. Following appropriate placement of the needle, once again dispersion of the contrast is observed (Fig. 5). If it is appropriate, local anesthetic and corticosteroid solution is injected similar to the lumbar transforaminal epidural injection.

To perform lumbar transforaminal epidural injections with an oblique approach, the patient and the fluoroscopy unit are rotated as needed to provide an oblique projection of the pedicle on the side of the targeted nerve root (222, 223). The oblique position is achieved by fluoroscopic imaging with adjustment until the superior articular process is seen between the anterior and posterior edge of the vertebral body and the base of the articular process is in line with the pedicle. A needle is inserted slightly above the superior articular process and directed toward the base of the pedicle, advancing slowly until contact is made with the bone below the pedicle. Following this, contrast is injected slowly and the dispersal pattern of the nerve root is assessed.

In any of the above-described techniques, if paresthesia is observed, the needle must be withdrawn slightly approximately a millimeter or so and contrast injected. Multiple types of patterns of nerve root or epidural filling are shown in Fig. 6. Injection of transforaminal epidural steroid may provide useful information by a provocative response de-

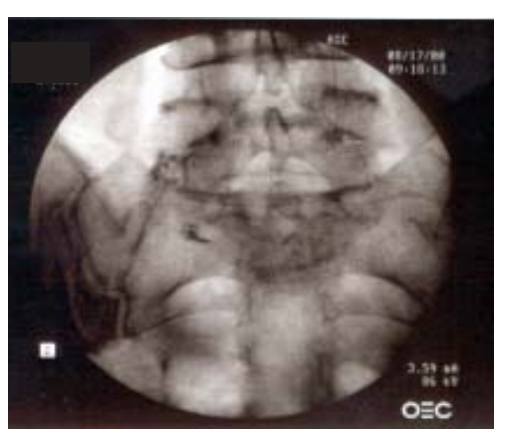

A. Single-needle positioning into SI foramen

Fig. 5. Transforaminal SI injection fined as pain occurring in response to mechanical or chemical stimulation, followed by an analgesic response upon injection of local anesthetic. Similarly, the early development of nerve root blocks was to diagnose the source of radicular pain when imaging studies suggested possible compression of several roots $(73-79,81,222-224)$.

\section{CONTROVERSIES}

Transforaminal epidural injections have been associated with controversy since their introduction, though they have been received with enthusiasm. In the early 1990s, the utility of selective nerve root blocks or transforaminal injections was limited to diagnostic purposes. In the later part of the $20^{\text {th }}$ century, its role for therapeutic purposes was defined. Thus, in the new millennium, transforaminal injections are not only accepted as part of medical practice by many physicians specializing in pain management but the technique is preached as state of the art. In fact, transforaminal epidural injections not only in the lumbar spine but also in the cervical spine have been awarded with specific codes in CPT 2000 (225). Multiple aspects of the evolution and occasional controversy concerning transforaminal epidural injections in managing low back pain include terminology and technique; diagnostic rationale and accuracy; therapeutic rationale and efficacy, frequency and number of injections; and cost effectiveness.

\section{Terminology and Technique}

The terminology describing nerve root injections has varied from transforaminal epidural to selective nerve root block, selective nerve root sleeve injection, selective epidural, selective spinal nerve block, or selective ventral ra-

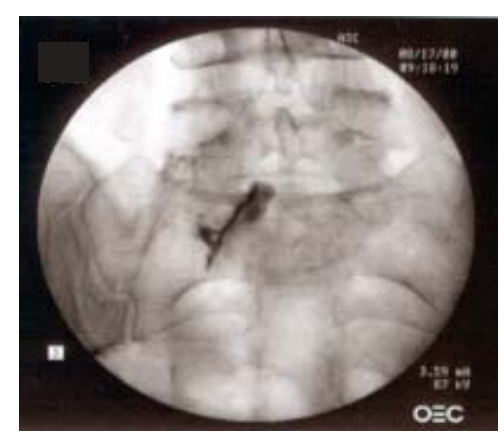

B. Outline of SI, nerve root following contrast injection extending caudally and cephalad 


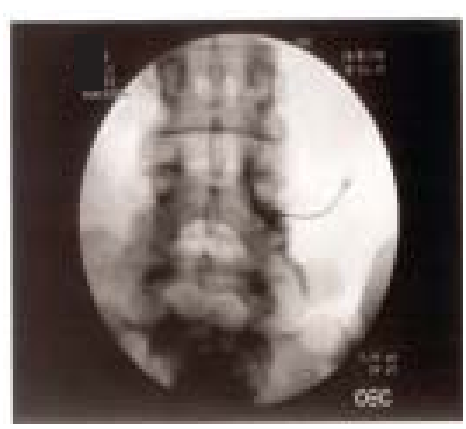

A

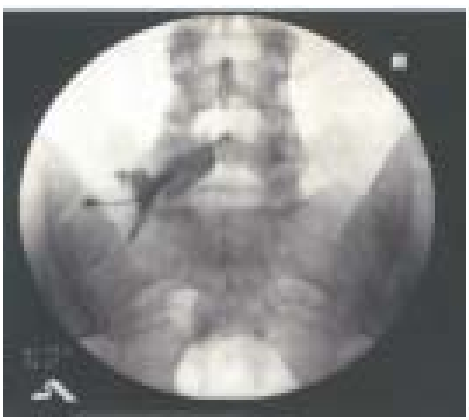

D

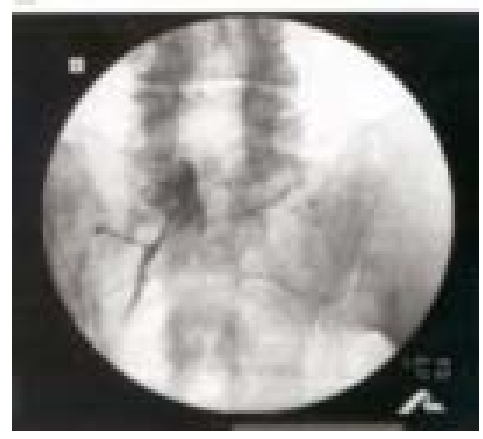

G

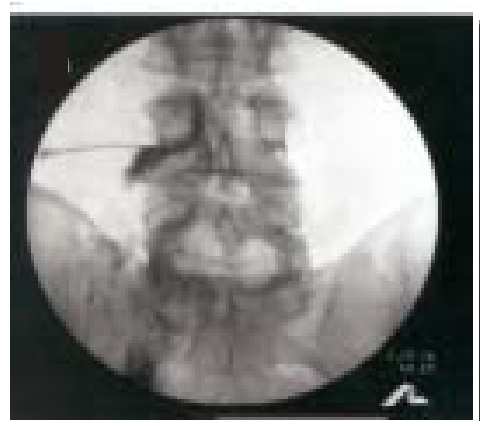

B

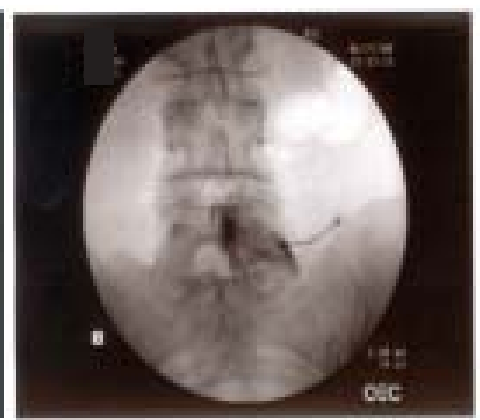

E

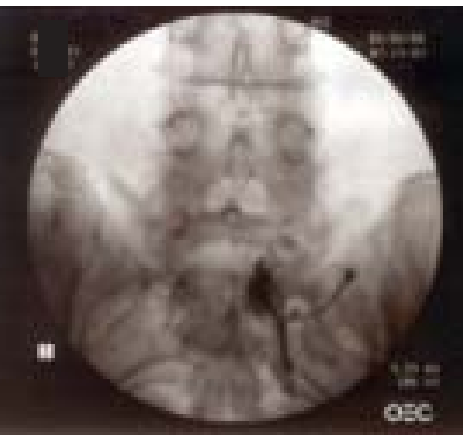

$\mathrm{H}$

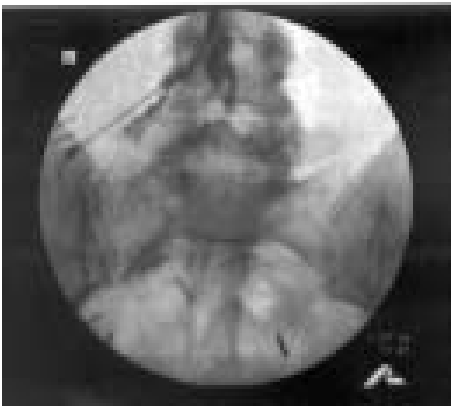

C

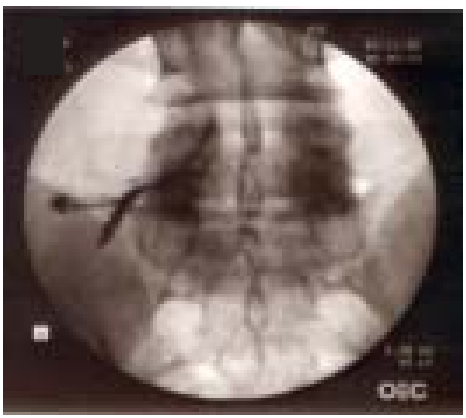

F

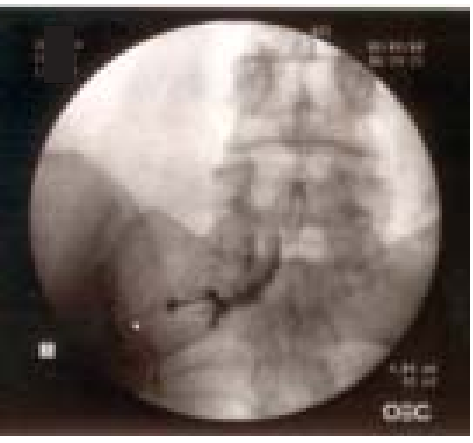

I

Fig. 6. Multiple types of contrast dispersion patterns of transforaminal epidural injections
A-C: $\quad$ L4 selective
D-F: $\quad$ L5 selective
G-I: $\quad$ SI selective 
mus block. As discussed, it appears that selective nerve root block is not an appropriate term for either the diagnostic or therapeutic procedure. For the diagnostic procedure, selective spinal nerve block or selective ventral ramus block may be the most appropriate term. Similarly for the therapeutic procedure, transforaminal epidural injection or selective epidural injection is appropriate.

The term selective nerve root sleeve injection has varied, depending on the location of the injection, the purpose of the injection and the philosophy of the physician performing the procedure. The question has been raised by Furman (226) whether it is really possible to do a selective nerve root block (226). A brief review of the anatomy once again shows that the ventral and dorsal segment roots join to form the segmental spinal nerve traversing the neural foramen, which outside the foramen divides into the dorsal and ventral rami (89). Thus, early studies on selective nerve root injections described an extra foraminal approach, in which a needle is advanced at right angles to the spinal nerve outside the neural foramen (224). Localization of the needle adjacent to the nerve relies on leg pain provocation, presumably resulting from penetration of the nerve root by the needle. However, transforaminal injections result in the medication's flowing to the epidural space. In a sense, a selective epidural injection is a variation of a selective nerve root injection. Injection of contrast into the epiradicular membrane will not only outline the nerve root, but also the ganglion, spinal nerve, and ventral ramus. Proximally, contrast will flow around the dural sac at the takeoff of the nerve root. If injected outside the epiradicular membrane, contrast will spread in the epidural fat and therefore be of limited diagnostic value (222, 224). A selective epidural injection does differ from a selective nerve root injection, and the goal is to inject into the epiradicular tissues. The spread of the injectate solutions will depend on the anatomy of the epiradicular membrane, which is an extension of the epidural space, leading to the term selective epidural injection, now universally accepted as transforaminal epidural injection $(222,224$, 225).

For a selective nerve root block, injection should be isolated immediately outside the neural foramina, before the rami divide, which will block the segmental spinal nerve. However, this would not be considered a transforaminal epidural injection. In addition, this injection would also anesthetize the dorsal ramus and all of its innervated structures, including the facet joint. To further improve selectivity, the block should be performed more laterally along the ventral ramus, which would be considered as a periph- eral block in the United States, similar to injection outside the neural foramina. Thus, a nerve root block may not be as selective as it sounds; hence, the diagnostic procedure should always be performed extraforaminally and away from the nerve root level. Consequently, the terminology selective nerve root block "may not be fitting", as this is not a diagnostic procedure and perhaps should rather be termed selective spinal nerve block or selective ventral ramus block (226).

A selective epidural has been described as having two major advantages over selective nerve root technique (224). The first is that the selective epidural injection with the transforaminal approach avoids contact with the nerve root, minimizing the potential for neural injury, thus obviating reliance on leg pain provocation from needle contact, and confirming needle localization with contrast-enhanced images demonstrating an outline of the nerve $(222,228)$. A second advantage is that in a selective epidural injection the transforaminal approach ensures that the injection incorporates all of the sites where pathology can affect the nerve from the disk level in the subarticular zone out lateral to the extraforaminal zone $(222,228)$. Thus, if the pathology causing the patient's symptoms is paramedian disc herniation, the so-called selective nerve root injection, selective spinal nerve block or selective ventral ramus block may fail to anesthetize a portion of the nerve generating the pain, potentially leading to a false-negative result. In addition, a selective epidural injection anesthetizes not only the spinal nerve itself but also all its branches. Despite its name, this injection is anything but selective. However, it is also argued that any lesion that affects a nerve root also necessarily affects its dural sleeve and therefore is a potential cause of axial pain (222). Thus, a selective epidural injection is considered potentially useful in diagnosing axial pain. In addition, relief of both axial and radicular pain with a selective epidural injection suggests that the same lesion is responsible for both. However, one cannot be certain that the axial component of pain is arising from structures above and/or below the injected level $(222,224)$. Thus, in patients with predominantly axial pain, to accurately identify the source of pain, injection of facet joints and discs may be essential, depending on the clinical situation. It is also probable that, given the anatomy of the spinal nerve and its branches, a transforaminal epidural injection will partially anesthetize the dura, including the dural nerve root sleeves up to two segments caudally and one segment rostrally, the posterior longitudinal ligament, and intervertebral disc at the same level and one segment rostrally, and the facet joints at the same level of the nerve and one segment below (224). Thus, it is important 
to differentiate whether, if the injection is performed to diagnose radicular pain, it is also anesthetizing various other structures, thus relieving axial pain. This may not be an issue if the injection is performed for radicular pain, as these structures are sources of axial pain, not radicular pain.

A transforaminal epidural injection elicits a provocative pain response resulting from contrast injection, followed by the analgesic response resulting from injection of local anesthetic and/or corticosteroids $(222,224)$. In evaluation of the provocation response, the location and character of the response and its relationship to the patients' usual and typical symptoms is crucial. In addition, the onset of provocative pain should be related to where the leading edge of the contrast solution is when the pain begins (222). In addition, normal epidural tissue is not painful even with the gentle stimulation of contrast solution and, in the absence of scar tissue, pain provocation indicates that the tissue stimulated is irritated $(222,224)$. O'Neill and Derby (224) described that early pain provocation with contrast still in the foramen suggests foraminal stenosis or foraminal disc herniation, in contrast to leg pain provocation, when the contrast approaches the disc above, which is consistent with a paramedian disc herniation. Analgesic response is also important. Thus, following the injection, the effect of local anesthetic injected or the symptoms addressed and provoked by mechanical stimulation must be assessed. Studies on selective nerve root injections have used the criteria for a positive analgesic response to be from $80 \%$ to $100 \%$ relief $(80,222)$. However, the significance of lesser degrees of pain relief and response to an injection is uncertain at this time. In addition, corticosteroid response which may provide important information (80), should also be evaluated

The results may be confounded by various factors leading to both false-positive and false-negative results with either transforaminal selective epidural or spinal nerve block, including changes in CNS nociceptive processing that occur with chronic pain, psychological factors, and placebo responses $(222-224,228,229)$. In this respect a number of studies have evaluated the clinical utility of selective epidural and selective nerve root injections. Individual studies investigating the predictive value of pain provocation, analgesic response with local anesthetic injection, and prolonged pain relief from corticosteroid in evaluating patients with radiculopathy suggest that, if a patient has concordant or exact provoked pain response to injection of contrast, complete pain relief following injection of local anesthetic, and a prolonged steroid response (greater than 1 week), the injected nerve root is mediating the patient's symptoms; and that a good result can be expected from surgical decompression, assuming a correctable lesion is demonstrated on imaging studies $(75,81,222,224)$. In contrast, if provocative response is a discordant pain, and incomplete immediate pain relief, without prolonged corticosteroid response, it is presumed that the injected nerve is probably not mediating the patient's symptoms, and another ordinate pain generator should be searched for. Similarly, with an intermediate type of response, a multitude of possibilities exist, with the possibilities that multiple nerve roots may be involved, or the patient may not have radicular pain (224). However, if the clinical situation is highly suggestive of radiculitis, a repeat injection is sought, probably with a control injection at an adjacent nerve, which may provide a better result with a negative control injection and positive response with an active injection, thus demonstrating a true positive response.

\section{Diagnostic Rationale}

Nerve root block was the term first developed to describe the technique for diagnosing the source of radicular pain when imaging studies suggested possible compression of several roots. Early studies of selective nerve root injections described an extraforaminal approach, in which the needle is advanced at right angles to the spinal nerve outside the neuroforamina, thus relying upon leg pain provocation, presumably resulting from penetration of the nerve by the needle (224). Subsequently, a variation of this procedure termed selective epidural, which is performed transforaminally, has emerged. It is known that nerve roots as they leave the dura to enter the foramen, and as they come from the spinal nerve, carry an extension of the dura with them, which becomes the epineurium of the spinal nerve. The epineurium is, in turn, enveloped by an epiradicular sheath, which is an extension of the anterior and posterior epidural membranes $(80,226)$. Thus, injection of contrast into the epiradicular membrane will not only outline the nerve root, but also outline the dorsal root ganglion, spinal nerve, and ventral ramus, with proximal flow of the contrast extending around the dural sac at the origin of the nerve root, thus limiting the diagnostic value. However, a number of studies that evaluated the clinical utility of selective epidural and selective nerve root injections, investigating pain provocation and pain relief, have demonstrated favorable results with utility of both selective nerve root blocks by the extra-foraminal approach and selective epidural injections by the transforaminal approach. Thus, the usefulness of a selective nerve root block by the extraforaminal approach or of selective epidural injection by the transforaminal approach is primarily related 
to the associated provocative and analgesic responses, even though the contrast-enhanced images from the injection can reveal pathological findings.

The development of new coding (225) for selective epidural injections justifies only the transforaminal epidural injections, at least in the United States. The selective nerve root blocks, either termed selective spinal nerve block or selective ventral ramus block, no longer have CPT codes to report the procedure appropriately to payors in the United States, thus requring interventional pain physicians to utilize a peripheral nerve block code.

\section{Therapeutic Rationale}

The clinical profile of the therapeutic efficiency of transforaminal epidural injections not only includes a randomized, double-blinded, controlled study but also includes one prospective study, and multiple retrospective and observational studies with a favorable profile (79-86). Thus far, there are no reports showing lack of response to therapeutic transforaminal epidural injections. In fact, this route of administration of corticosteroids is rapidly emerging as the technique of choice, even though enthusiasm has been dampened by recent governmental regulations and with the lack of recognition by payors in certain institutional settings in the United States.

Transforaminal lumbar epidural steroid injections have a better profile in terms of therapeutic efficiency in managing chronic low back pain than blind interlaminar epidural injections, as well as fluoroscopically directed caudal epidural injections (79-86). There is also a preponderance of evidence showing the clinical efficiency of caudal epidural steroid injections, though it has not been the same for blind interlaminar epidural injections $(2,3,8,11,12)$. Thus far, there is no published evidence demonstrating the effectiveness of fluoroscopically directed interlaminar epidural corticosteroid administration in the lumbar spine. In addition, experimental evidence thus far supports clinical application of epidural steroids (132-135).

\section{Type and Dosage of Drugs}

The major controversy in the arena of epidural injection surrounds the administration of corticosteroids. The majority of the attention in the literature has been focused on the complications attributed to the use of epidural steroids, which essentially arise from false impressions. However, transforaminal lumbar epidural steroid injections have specific advantage in that not only is the administration target specific but it also limits the dosage of steroids to a lower dose due to the target specificity of the injection and delivery of the medication. Thus, at least this aspect should dampen the criticism against epidural corticosteroids. Frequency, as well as total number, of transforaminal lumbar epidural injections is controversial and has not been addressed. Most criticism is extrapolated from the criticism about lumbar interlaminar and caudal epidural corticosteroid administration, which is based not only on a lack of understanding of the pathophysiology or pharmacologic profile of steroids, but also on personal preference and bias. Based on the present evidence, it appears reasonable to continue lumbar transforaminal epidural injections at appropriate intervals after initial stabilization, leading to either continued increase in duration or maintenance at safe and reasonable intervals of at least 2 months. At this time, it should be realized that it is not only unrealistic but unfair to presume that neural blockade will provide permanent relief with one treatment. In addition, arguments about the therapeutic window provided by the relief of transforaminal epidural injections, which is considered short term, are also not realistic, specifically in managing chronic low back pain, as most of these patients have undergone a multitude of therapeutic modalities, including surgical interventions, blind interlaminar epidural injections and rehabilitation modalities, along with drug therapy.

While the diagnostic utility of transforaminal epidural injection is somewhat riddled with controversy, its therapeutic role is well defined. Therapeutic transforaminal epidural injection reliably anesthetizes the dura, including the dural nerve root sleeves up to two segments caudally and one segment rostrally. In the therapeutic arena where the patient has axial pain, radicular pain, or a combination of both, this type of activity is not only reasonable but desirable. Some consider a therapeutic injection as an isolated treatment, which has the potential to provide both longterm pain relief and restoration of function $(3,12,79,80$, 222). However, some clinicians feel that the primary role of a therapeutic injection is to provide short-term pain relief, allowing a window of opportunity for rehabilitation. However, this philosophy has been discounted (159, 170, $230,231)$. In addition, when the procedure is performed for therapeutic purposes, a larger volume of injectate can be used with the transforaminal approach. The therapeutic role of selective spinal nerve block or ventral ramus block has not been demonstrated.

\section{Outcomes and Cost Effectiveness}

Transforaminal epidurals may be criticized for the lack of 
preponderance of evidence derived from controlled, prospective, randomized studies. However, Concato et al (176) showed that well-designed observational studies were equal to randomized studies. Thus, transforaminal epidural steroid injections have been shown to be effective in all studies available, including randomized, prospective, and retrospective. In addition, the evidence is at least equal and in some cases superior to the evidence available from effectiveness studies of interlaminar and caudal epidural injections. Last but not least, the cost effectiveness of transforaminal epidural injections is superior to that of blind interlaminar epidural corticosteroids, caudal epidural corticosteroids, and a multitude of other modalities of treatments (Fig. 3). Considering the outcomes and cost-benefit analysis, it appears that lumbar transforaminal epidural injections, if provided appropriately, are justified.

\section{CONCLUSION}

Chronic low back pain is a major health care problem and burden on society. Much of the controversy and confusion surrounding neural blockade in general and transforaminal epidural steroid injections in particular stems from the emphasis on biopsychosocial approach and inappropriate selection of patients. However, it appears that modern arguments and approaches, for whatever reason, invariably exclude the bio - aspect from the biopsychosocial approach. In addition, Lord et al (221) have attempted to demystify this inordinate emphasis by demonstrating the role of physical management. Considering the convincing and cumulative evidence available in the literature on transforaminal epidural steroids, though in their infancy, the effectiveness of transforaminal epidural steroid injections is similar, if not superior, to various other modalities of treatments available in managing chronic low back pain. Thus, based on the preliminary literature while awaiting further double-blind, randomized, controlled studies, continued use of transforaminal epidural steroid injections is justified.

\section{REFERENCES}

1. Cathelin F. Mode d'action de la cocaine injecte dons l'escape epidural par le proceda dee canal sacre. $C R$ Soc Biol 1901; 53:478-479.

2. Bogduk N, Christophidis N, Cherry D et al. Epidural use of steroids in the management of back pain. Report of Working Party on Epidural Use of Steroids in the Management of Back Pain. Canberra, Commonwealth of Australia, National Health and Medical Research Council, 1994, pp 1-76.

3. Manchikanti L. The role of neural blockade in the management of chronic low back pain. Pain Digest 1999; 9:166-181.
4. Bogduk N. Epidural steroids for low back pain and sciatica. Pain Digest 1999; 9:226-227.

5. Nash TP. Current guidelines in the use of epidural steroids in the United Kingdom. Pain Digest 1999; 9:231-232.

6. Abram SE. Current guidelines in the use of epidural steroids in the United States of America. Pain Digest 1999; 9:233-234.

7. Raj PP. Epidural steroid injections. Pain Digest 1999; 9:235-240.

8. Koes BW, Scholten RJPM, Mens JMA et al. Efficacy of epidural steroid injections for low back pain and sciatica: A systematic review of randomized clinical trials. Pain 1995; 63:279-288.

9. Van Zundert J, Plaghki L, Adriaensen H. Conclusions: Value of epidural corticosteroid injections in low back pain and sciatica. Pain Digest 1999; 9:248-251.

10. Watts RW, Silagy CA. A meta-analysis on the efficacy of epidural corticosteroids in the treatment of sciatica. Anaesth Intens Care 1995; 23:564-569.

11. Koes BW, Scholten R, Mens JMA et al. Epidural steroid injections for low back pain and sciatica. An updated systematic review of randomized clinical trials. Pain Digest 1999; 9:241-247.

12. Manchikanti L, Singh V, Bakhit, $\mathrm{C}$ et al. Interventional techniques in the management of chronic pain: Part 1.0. Pain Physician 2000; 3:7-42.

13. Spitzer WO, Leblanc FE, Dupuis M (eds). Quebec Task Force on Spinal Disorders. Scientific approach to the assessment and management of activity-related spinal disorders: A monograph for clinicians. Spine 1987; (suppl) 12:1-59.

14. Deyo RA, Tsui-Wu YJ. Descriptive epidemiology of low back pain and its related medical care in the United States. Spine 1987; 12:264-268.

15. Lawrence RC, Helmick CG, Arnett FC. Estimates of the prevalence of arthritis and selected musculoskeletal disorders in the United States. Arthritis \& Rheumatism 1998; 41:778-799.

16. Gureje O, Von Korff M, Simon GE et al. Persistent pain and well being. A World Health Organization Study in Primary Care. JAMA 1998; 280:147-151.

17. Loney PL, Stratford PW. The prevalence of low back pain in adults. A methodological review of the literature. Physical Therapy 1999; 79:384-396.

18. Leboeuf-Yde C, Lauritsen JM. The prevalence of low back pain in the literature. A structured review of 26 Nordic studies from 1954 to 1993. Spine 1995; 20:2112-2118.

19. Bressler HB, Keyes WJ, Rochon PA et al. The prevalence of low back pain in the elderly. A systematic review of the literature. Spine 1999; 24:1813-1819.

20. Waddell G. The back pain revolution. Edinburgh, Churchill Livingston, 1998; pp 85-101.

21. Postacchini F. Results of surgery compared with conservative management for lumbar disc herniations. Spine 1996; 21:1383-1387. 
22. Fritsch EW, Heisel J, Rupp S. The failed back surgery syndrome. Reasons, intraoperative findings, and longterm results: A report of 182 operative treatments. Spine 1996; 21:626-633.

23. Turner JA, Ersek M, Herron L et al. Surgery for lumbar spinal stenosis, attempted meta-analysis of the literature. Spine 1992; 17:1-7.

24. Waddell G, Kummel EG, Lotto WN et al. Failed lumbar disc surgery and repeat surgery following industrial injury. J Bone Joint Surg (Am) 1979; 61:201207.

25. Davis H. Increasing rates of cervical and lumbar spine surgery in the United States, 1979-1990. Spine 1994; 19:1117-1124.

26. Gibson JNA, Grant IC, Waddell G. The Cochrane review of surgery for lumbar disc prolapse and degenerative lumbar spondylosis. Spine 1999; 24:18201832.

27. Leigh JP, Markowitz SB, Fahs M et al. Occupational injury and illness in the United States. Estimates of costs, morbidity, and mortality. Arch Inter Med 1997; 157:1557-1568.

28. Van Korff M, Dworkin SF, Le Resche L et al. An epidemiologic comparison of pain complaints. Pain 1988;32:173-183.

29. Manchikanti L. Epidemiology of low back pain. Pain Physician 2000; 3:167-192.

30. Fanuele JC, Birkmeyer NJ, Abdu WA et al. The impact of spinal problems on the health status of patients. Spine 2000; 25:1509-1514.

31. Manchikanti L. State of interventional pain medicine. Pain Physician 2000; 3:241-255.

32. Cherkin D, Deyo R, Loeser J et al. An international comparison of back surgery rates. Spine 1994; 19:1201-1206.

33. Keskimäki I, Aro S, Teperi J. Regional variation in surgical procedures rates in Finland. Scand J Soc Med 1994; 22:132-138.

34. Seitsalo S, Keskimäki I, Paavolainen P. Back surgery rates in Finland 1987-1994: Increasing trends; regional variations. Fin J Orthop Traumatol 1996; 19:199-204.

35. Madsen M, Andersen TF, Roepstorff $\mathrm{C}$ et al. Rates of surgery in the Nordic countries: Variation between and within nations. NOMESCO, 1994. Copenhagen

36. Deyo RA, Cherkin D, Conrad D et al. Cost, controversy, crisis: low back pain and the health of the public. Annu Rev Public Health 1991; 12:141-156.

37. Volinn E, Mayer J, Diehr P et al. Small area analysis of surgery for low-back pain. Spine 1992; 17:575579.

38. Kostuik J. Spinal surgery of the future. Presidential address. Spine 1992; 17(suppl): 66-70.

39. Lewis C. Variations in the incidence of surgery. $N$ Engl J Med 1969; 281:880-884.

40. Wennberg J, Gittelsohn A. Variations in medical care among small areas. Sci Am 1982; 246: 120-134.
41. Jonsson B. Repeat decompression of lumbar nerve roots: A prospective two-year evaluation. J Bone Joint Surg [Br] 1993; 75:894-897.

42. Keskimäki I, Seitsalo S, Osterman $\mathrm{H}$ et al. Reoperations after lumbar disc surgery. Spine 2000; 25:1500-1508.

43. Cassidy D, Carroll L, Cote P. The Saskatchewan Health and Back Pain Survey. Spine 1998; 23:1860-1867.

44. Van Den Hoogen HJM, Koes BW, Deville W et al. The prognosis of low back pain in general practice. Spine 1997; 22:1515-1521.

45. Croft PR, Papageorgiou AC, Thomas E et al. Shortterm physical risk factors for new episodes of low back pain. Prospective evidence from the South Manchester Back Pain Study. Spine 1999; 24:1556-1561.

46. Carey TS, Evans A, Hadler N et al. Care-seeking among individuals with chronic low back pain. Spine 1995; 20:312-317.

47. Miedema HS, Chorus AMJ, Wevers CWJ et al. Chronicity of back problems during working life. Spine 1998; 23:2021-2029.

48. Thomas E, Silman AJ, Croft PR et al. Predicting who develops chronic low back pain in primary care. A prospective study. Br Med J 1999; 318:1662-1667.

49. Anderson GBJ, Svensson HO. The intensity of work recovery in low back pain. Spine 1983; 8:880-887.

50. Pasquier MM, Leri D. Injection intra-et extradudrals de cocaine a dose minime daus le traitments dela sciatique. Bull Gen Ther 1901; 142:196.

51. Sicard MA. Les injections medicamenteuse extradurales par voie saracoccygiene. Comptes Renues des Seances de la Societe de Biologie et de ses Filliales (Paris) 1901; 53:396.

52. Viner N. Intractable sciatica - the sacral epidural injection - an effective method of giving relief. Can Med Assoc J 1925; 15:630-634.

53. White AH, Derby R, Wynne G. Epidural injections for diagnosis and treatment of low back pain. Spine 1980; 5:78-86.

54. Fredman B, Nun MB, Zohar E et al. Epidural steroids for treating "failed back surgery syndrome:" Is fluoroscopy really necessary? Anesth Analg 1999; 88:367372.

55. Mehta M, Salmon N. Extradural block. Confirmation of the injection site by X-ray monitoring. Anaesthesia 1985; 40:1009-1012.

56. Burn JM, Guyer PB, Langdon L. The spread of solutions injected into the epidural space: A study using epidurograms in patients with lumbosciatic syndrome. Br J Anaesth 1973;45:338-345.

57. Nishimura N, Khahara T, Kusakabe T. The spread of lidocaine and 1-131 solution in the epidural space. Anesthesiology 1959;20:785-788.

58. Hodgson PSA, Mack B, Kopacz D et al. Needle placement during lumbar epidural anesthesia deviates toward the non-dependent side (abstract). Reg Anesth 1996;21:26. 
59. Robechhi A, Capra R. L'idrocortisone (composto F). Prime esperienze cliniche in campo reumatologico . Minerva Med 1952; 98:1259-1263.

60. Lievre JA, Block-Mechel H, Pean G, et al. L'hydrocortisone en injection locale. Rev Rhum 1953; 20:310-311.

61. Biella A, Cocognini P. L'acetato di idrocortisone nel trattamento della sindrome sciatalgica. Minerva Med $1954 ; 1: 1863-1865$.

62. Canale L. Il desametazone per via eidurale sacrale nelle lombosciataligie. Gaz Med Ital 1963; 122:210213.

63. Cappio M. Il trattamento idrocortisonico per via epidurale sacrale delle lombosciatalgie. Reumatismo 1957; 9:60-70.

64. Cappio M, Fragasso V. Osservazioni sull'uso dell'idroscortisone per via eidurale ed endorachidea nelle lombosciatalgie. Riforma Med 1955; 22:605-607.

65. Cappio M, Fragasso V. Il prednisone per via epidurale sacrale nelle lombosciatalgie. Reumatismo 1957; 5:295-298.

66. Fragasso V. Il prednisolone idrosolubile per via epidurale sacrale nelle lombosciatalgie. Gaz Med Ital 1959; 118:358-360.

67. Gerest MF. Le traitement de la nevralgie sciatique par les injections epidurales d'hydrocortisone. JMed Lyon 1958; 261-264.

68. Gilly R. essai de traitement de 50 cas de sciatiques et de radiculalgies lombaires par le Clestene chronodose en infiltrations paradiculaire. Marseille Medicale 1970; 107:341-345.

69. Renier JC. L'infiltration epidurale par le premier trou sacre posterieur. Revue du Rhumatisme et des Maladies Osteo-articulaire 1959; 26:526-532.

70. Macnab I. Negative disc exploration: An analysis of the causes of nerve-root involvement in sixty-eight patients. J Bone Joint Surg 1971; 53:891-903.

71. Kikuchi S, Hasue M. Combined contrast studies in lumbar spine disease - myelography (peridurography) and nerve root infiltration. Spine 1988; 13:1327-1331.

72. Tajima T, Furukawa K, Kuramochi E. Selective lumbosacral radiculography and block. Spine 1980; 5:6877.

73. Dooley JF, McBroom RJ, Taguchi T et al. Nerve root infiltration in the diagnosis of radicular pain. Spine 1988; 13:79-83.

74. Haueisen C, Smith B, Myers SR et al. The diagnostic accuracy of spinal nerve injection studies. Their role in the evaluation of recurrent sciatica. Clin Orthop 1985; 198:179-183.

75. Herron LD. Selective nerve root blocks in patient selection for lumbar surgery-surgical results. J Spinal Disord 1989; 2:75-79.

76. Krempen JF, Smith B. Nerve root injection: A method for evaluating the etiology of sciatica. J Bone Joint Surg 1974; 56A:1435-1444.
77.

Stanley D, McLoren MI, Evinton HA et al. A prospective study of nerve root infiltration in the diagnosis of sciatica. A comparison with radiculopathy, computed tomography and operative findings. Spine 1990; 15:540-543.

78. Kikuchi S, Hasue M, Nishiyama K. Anatomic and clinical studies of radicular symptoms. Spine 1984;9:23-30.

79. Manchikanti L, Pakanati RR, Pampati V. Comparison of three routes of epidural steroid injections in low back pain. Pain Digest 1999;9:277-285.

80. Derby R, Kine G, Saal JA et al. Response to steroid and duration of radicular pain as predictors of surgical outcome. Spine 1992;17 (Suppl):176-183

81. Weiner BK, Fraser RD. Foraminal injection for lateral lumbar disc herniation. J Bone Joint Surg 1997;79B:804-807.

82. Devulder, J. Transforaminal nerve root sleeve injection with corticosteroids, hyaluronidase, and local anesthetic in the failed back surgery syndrome. J Spinal Disord 1998;11:151-154.

83. Lutz GE, Vad VB, Wisneski RJ. Fluoroscopic transforaminal lumbar epidural steroids: An outcome study. Arch Phys Med Rehabil 1998; 79:1362-1366.

84. Slipman CW, Plastaras CT, Palmitier RA et al. Symptom provocation of fluoroscopically guided cervical nerve root stimulation. Are dynatomal maps identical to dermatomal maps? Spine 1998; 23:2235-2242.

85. Lutz GE, Vad VB, Wisneski RJ. Fluoroscopic transforaminal lumbar epidural steroids. An outcome study. Presented at ISIS 7th Annual Scientific Meeting, Las Vegas, NV, August 1999.

86. Riew KD, Yin Y, Gilula L et al. Can nerve root injections obviate the need for operative treatment of lumbar radicular pain? A prospective, randomized, controlled, double-blind study. Proceedings of North American Spine Society 16th Annual Meeting. Chicago, 1999, pp 94-95.

87. Bogduk N. The innervation of the lumbar spine. Spine 1983;8:286-293.

88. Bogduk N. In Clinical Anatomy of the Lumbar Spine and Sacrum, ed 3. New York, Churchill Livingstone, 1997, pp 55-66.

89. Bogduk N. Clinical Anatomy of the Lumbar Spine and Sacrum. New York, Churchill Livingstone, 1997, pp 127-144.

90. Hogan QH. Epidural anatomy examined by cryomicrotome section. Influence of age, vertebral level and disease. Reg Anesth 1996;21:295-306.

91. Savolaine ER, Pandya JB, Greenblat SH et al. Anatomy of the human lumbar epidural space: New insights using CT-Epidurography. Anesthesiology 1988;68:217220.

92. Weinstein SM, Herring SA, Derby R: Epidural steroid injections. Spine 1995; 20:1842-1846.

93. Bose K, Balasubramanian P. Nerve root canals of the lumbar spine. Spine 1984; 9:16-18. 
94. Kuslich SD, Ulstrom CL, Michael CJ: The tissue origin of low back pain and sciatica: A report of pain response to tissue stimulation during operation on the lumbar spine using local anesthesia. Orthop Clin North Am 1991;22:181-187.

95. Mixter WJ, Barr JS: Rupture of the intervertebral disc with involvement of the spinal canal. $N$ Eng $\mathrm{J} \mathrm{Med}$ 1934;211:210-215.

96. Sehgal N, Fortin J. Internal disc disruption and low back pain. Pain Physician 2000; 3:143-157.

97. Saal JA, Saal JS, Herzog RJ. The natural history of lumbar intervertebral disc extrusions treated nonoperatively. Spine 1990; 15:683-686.

98. Bush K, Cowan N, Katz DE et al. The natural history of sciatica associated with disc pathology: A prospective study with clinical and independent radiologic follow-up. Spine 1992; 17:1205-1210.

99. Maigne JY, Rime B, Delinge B. Computed tomographic follow-up study of forty-eight cases of nonoperatively treated lumbar intervertebral disc herniation. Spine 1992; 17:1071-1074.

100. Delauche-Cavallier M-C, Budet C, Laredo J-D et al Lumbar disc herniation: Computed tomography scan changes after conservative treatment of nerve root compression. Spine 1992; 17:927-933.

101. Boden SD, Davis DO, Dina TS et al. Abnormal magnetic-resonance scans of the lumbar spine in asymptomatic subjects. J Bone Joint Surg 1990; 72A:403408.

102. Jensen MC, Bran-Zawadzki MN, Obucjowski N et al. Magnetic resonance imaging of the lumbar spine in people without back pain. NEngl J Med 1994; 331:6973.

103. Wiesel SW. A study of computer-assisted tomography. 1. The incidence of positive CAT scans in an asymptomatic group of patients. Spine 1986; 9:549551.

104. Devor M. Pain arising from the nerve root and the dorsal root ganglia and chronically injured axons: A physiological basis for the radicular pain of nerve root compression. Pain 1977; 3:25-41.

105. Olmarker K, Rydevik B, Holm S. Edema formation in spinal nerve roots induced by experimental, graded compression: An experimental study on the pig cauda equina with special reference to differences in effects between rapid and slow onset of compression. Spine 1989; 14:569-573.

106. Yoshizawa H, Nakai S, Koboyashi S et al. Intraradicular edema formation as a basic factor in lumbar radiculopathy. In Weinstein JN, Gordon SL (Eds). Low Back Pain: A Scientific and Clinical Overview. Rosemont, IL, American Academy of Orthopaedic Surgeons, 1996, pp 235-246.

107. Olmarker K, Rydevik B, Holm B et al. Effects of experimental graded compression on blood flow in spinal nerve roots: A vital microscopic study on the porcine cauda equina. J Orthop Res 1989; 7:817-823.
108. Olmarker K. Mechanical and biochemical injury of spinal nerve roots: An experimental perspective. In Weinstein JN, Gordon SL (Eds). Low Back Pain: A Scientific and Clinical Overview. Rosemont, IL, American Academy of Orthopaedic Surgeons, 1996, pp 215-233.

109. McCarron RF, Wimpee MW, Hudkins PG et al. The inflammatory effects of nucleus pulposus: A possible element in the pathogenesis of low back pain. Spine 1987; 12:760-764.

110. Saal JS, Franson RC, Dobrow R et al. High levels of inflammatory phospholipase A2 activity in lumbar disc herniations. Spine 1990; 15:674-678.

111. Kayama S, Konno S, Olmarker K et al. Incision of the annulus fibrosus induces nerve root morphologic, vascular, and functional changes. Spine 1996;21:25392543.

112. Chaoyang C, Cavanaugh JM, Ozaktay C et al. Effects of phospholipase $\mathrm{A}_{2}$ on lumbar nerve root structure and function. Spine 1997;22:1057-1064.

113. Bobechko WT, Hircsch C. Autoimmune response to nucleus pulposus in the rabbit. J Bone Joint Surg 1965; 47B:574-580.

114. Elves MW, Bucknill T, Sullivan MF. In vitro inhibition of leucocyte migration in patients with intervertebral disc lesions. Orthop Clin North Am 1975; 6:5965.

115. Gertzbein SD. Degenerative disk disease of the lumbar spine: Immunological implications. Clin Orthop 1977; 129:68-71.

116. Gertzbein SD, Tait JH, Devlin SR. The stimulation of lymphocytes by nucleus pulposus in patients with degenerative disk disease of the lumbar spine. Clin Orthop 1977; 123:149-154.

117. Gertzbein SD, Tile M, Gross A. Autoimmunity in degenerative disc disease of the lumbar spine. Orthop Clin North Am 1975;6:67-73.

118. Olmarker K, Blomquist J, Stromberg J et al. Inflammatogenic properties of nucleus pulposus. Spine 1995; 20:665-669.

119. Cavanaugh JM, Ozaktay AC, Vaidyanathan S. Mechano- and chemosensitivity of lumbar dorsal roots and dorsal root ganglia: An in vitro study. Trans Orthop Res Soc 1994; 19:109.

120. Kawakami M, Weinstein JN, Tamaki, et al. The difference in nociceptive potential of the nucleus pulposus and the anulus fibrosus. In Weinstein JN, Gordon SL (Eds). Low Back Pain: A Scientific and Clinical Overview. Rosemont, IL, American Academy of Orthopaedic Surgeons, 1996, pp 209-213.

121. Kawakami M, Tamaki T, Weinstein JN et al. Pathomechanism of pain-related behavior produced by allografts of intervertebral disc in the rat. Spine 1996; 21:2101-2107.

122. Kang JD, Georgescu HI, McIntyre-Larkin L et al. Herniated lumbar intervertebral discs spontaneously 
produce matrix metalloproteinases, nitric oxide, interleukin-6, and prostaglandin E2. Spine 1996; 21 : 271-277.

123. Olmarker K, Rydevik B, Nordborg C. Autologous nucleus pulposus induces neurophysiologic and histologic changes in porcine cauda equina nerve roots. Spine 1993; 181:1425-1432.

124. Gronblad M, Virri J, Tolonen J et al. A controlled immunohistochemical study of inflammatory cells in disc herniation tissue. Spine 1994; 19:2744-2751.

125. Jaffray D, O'Brien JP. Isolated intervertebral disc resorption: A source of mechanical and inflammatory back pain? Spine 1986; 11:397-401.

126. Kawakami M, Tamaki T, Hashizume $\mathrm{H}$ et al. The role of phospholipase A2 and nitric oxide in pain-related behavior produced by an allograft of intervertebral disc material to the sciatic nerve of the rat. Spine 1997; 22:1074-1079.

127. Marshall LL, Trethewie ER, Curtain CC. Chemical radiculitis: A clinical, physiological and immunological study. Clin Orthop 1977; 129:61-67.

128. Murphy RW. Nerve roots and spinal nerves in degenerative disk diseases. Clin Orthop 1977; 129:46-60.

129. Nygaard OP, Mellgren SI, Osterud B. The inflammatory properties of contained and noncontained lumbar disc herniation. Spine 1997; 22:2484-2488.

130. Yabuki S, Kikuchi S, Olmarker K et al. Acute effects of nucleus pulposus on blood flow and endoneurial fluid pressure in rat dorsal root ganglia. Spine 1998; 23:2517-2523.

131. Yabuki S, Igarashi T, Kikuchi S. Application of nucleus pulposus to the nerve root simultaneously reduces blood flow in dorsal root ganglion and corresponding hindpaw in the rat. Spine 2000; 25:1471-1476.

132. Lee HM, Weinstein JN, Meller ST et al. The role of steroids and their effects on phospholipase A2. An animal model of radiculopathy. Spine 1998; 23:11911196.

133. Olmarker K, Byrod G, Cornefjord M et al. Effects of methylprednisolone on nucleus pulposus-induced nerve root injury. Spine 1994; 19:1803-1808.

134. Hayashi N, Weinstein JN, Meller ST et al. The effect of epidural injection of betamethasone or bupivacaine in a rat model of lumbar radiculopathy. Spine 1998; 23:877-885.

135. Minamide A, Tamaki T, Hashizume $\mathrm{H}$ et al. Effects of steroids and lipopolysaccharide on spontaneous resorption of herniated intervertebral discs. An experimental study in the rabbit. Spine 1998; 23:870-876.

136. Manchikanti L, Bakhit CE, Pampati V. Role of epidurography in caudal neuroplasty. Pain Digest 1998;8:277-281.

137. Renfrew DL, Moore TE, Kathol MH et al. Correct placement of epidural steroid injections: Fluoroscopic guidance and contrast administration. Amer $J$ Neuroradiol 1991;12:1003-1007.
138. Stewart HD, Quinnell RC, Dann N. Epidurography in the management of sciatica. Br J of Rheum 1987; 26:424-429.

139. El-Khoury G, Ehara S, Weinstein JW et al. Epidural steroid injection: A procedure ideally performed with fluoroscopic control. Radiology 1988; 168:554-557.

140. Stitz MY, Sommer HM. Accuracy of blind versus fluoroscopically guided caudal epidural injection. Spine 1999; 24:1371-1376.

141. Sullivan WJ, Willick Se, Chira-Adisai W et al. Incidence of intravascular uptake in lumbar spinal injection procedures. Spine 2000; 25:481-486.

142. Manchikanti L, Bakhit CE, Pakanati RR et al. Fluoroscopy is medically necessary for the performance of epidural steroids. Anesth Analg 1999; 89:1326-1327.

143. Bromage RP, Benumof JL. Paraplegia following intracord injection during attempted epidural anesthesia under general anesthesia. Reg Anesth and Pain Med 1998; 23:104-107.

144. Krane EJ, Dalens BJ, Murat I et al The safety of epidurals during general anesthesia. Reg Anesth and Pain Med 1998; 23:433-438.

145. Saberski LR, Kondamuri S, Osinubi OYO. Identification of the epidural space: Is loss of resistance to air a safe technique? Regional Anesthesia 1997; 22:315.

146. Harley C. Extradural corticosteroid infiltration. A follow-up study of 50 cases. Ann Phy Med 1966;9:2228.

147. Rogers P, Nash T, Schiller D et al. Epidural steroids for sciatica. The Pain Clinic 1992; 5:67-72.

148. Kepes ER, Duncalf D. Treatment of backache with spinal injections for local anesthetics, spinal and systemic steroids. A review. Pain 1985; 22:33-47.

149. Benzon HT. Epidural steroid injections for low back pain and lumbosacral radiculopathy. Pain 1986; 24 : 277-295.

150. Haddox JD. Lumbar and cervical epidural steroid therapy . Anesth Clin North Am 1992; 10:179-203.

151. Breivik H, Hesla PE, Molnar I et al. Treatment of chronic low back pain and sciatica. Comparison of caudal epidural injections of bupivacaine and methylprednisolone with bupivacaine followed by saline. In Bonica JJ, Albe-Fesard D (Eds). Advances in Pain Research and Therapy. New York, Raven Press, 1976, Vol 1, pp 927-32.

152. Bush K, Hillier S. A controlled study of caudal epidural injections of triamcinolone plus procaine for the management of intractable sciatica. Spine 1991;16:572-575.

153. Yates DW. A comparison of the types of epidural injection commonly used in the treatment of low back pain and sciatica. Rheum Rehab 1978;17:181-186.

154. Beliveau P. A comparison between epidural anesthesia with and without corticosteroids in the treatment of sciatica. Rheum Phys Med 1971;11:40-43. 
155. Goebert HW, Jallo SJ, Gardner WJ et al. Painful radiculopathy treated with epidural injections of procaine and hydrocortisone acetate results in $113 \mathrm{pa}-$ tients. Anesth Analg 1961;140:130-134.

156. Dilke TFW, Burry HC, Grahame R. Extradural corticosteroid injection in the management of lumbar nerve root compression. Br Med J 1973;2:635-637.

157. Ridley MG, Kingsley GH, Gibson T. et al. Outpatient lumbar epidural corticosteroid injection in the management of sciatica. Br J Rheumatol 1988;27:10031007.

158. Snoek W, Weber H, Jorgensen B. Double-blind evaluation of extradural methyl/prednisolone for herniated lumbar disc. Acta Orthop Scand 1977;48:635-641.

159. Carette S, Lecaire R, Marcoux S et al. Epidural corticosteroid injections for sciatica due to herniated nucleus pulposus. N Engl J Med 1997;336:1634-1640.

160. Berman AT, Garbarinbo JL, Fisher SM et al. The effects of epidural injection of local anesthetics and corticosteroids in patients with lumbosciatic pain. Clin Orthop 1984;188:144-151.

161. Rosen CD, Kahanovitz N, Berstein R et al. A retrospective analysis of the efficacy of epidural steroid injections. Clin Orthop 1988;228:270-272.

162. Warr AC, Wilkinson JA, Burn JMB et al. Chronic lumbosciatica syndrome treated by epidural injection and manipulation. Practitioner 1977;209:53-59.

163. Swerdlow M, Sayle-Creer W. A study of extradural medication in the relief of three lumbosciatic syndromes. Anaesthesia 1970;25:341-345.

164. Jamison RN, VadeBoncouer T, Ferrante FM. Low back pain patients unresponsive to an epidural steroid injection: Identifying predictive factors. Clin J Pain 1991; 7:311-317.

165. Cuckler JM, Bernini PA, Wiesel SW et al. The use of epidural steroid in the treatment of radicular pain. $J$ Bone Joint Surg 1985;67:63-66.

166. Andrade A, Eckman E. The distribution of radiologic contrast media by lumbar translaminar and selective neural canals in normal human volunteers. Presented at the annual meeting of the International Spinal Injection Society, Keystone, CO, January 1992.

167. Saal JS, Saal JA. Comprehensive cervical and lumbar intra-spinal injection course. Stanford University School of Medicine, Stanford, California, July 11-12, 1998.

168. Koes BW, Bouter LM, Van Der Heijden GJMGV. Methodological quality of randomized clinical trials on treatment efficacy in low back pain. Spine 1995;20:228-235.

169. Van Tulder MW, Koes BW, Bouter LM. Conservative treatment of acute chronic nonspecific low back pain. A systematic review of randomized controlled trials of the most common interventions. Spine 1997; 22:21282156.

170. Bigos SJ, Boyer OR, Braen GR et al. Acute Low Back Problems in Adults. Clinical Practice Guideline Num- ber 4. AHCPR Publication No. 95-0642. Rockville, MD, Agency for Health Care Policy and Research, Public Health Service, US Department of Health and Human Services, December 1994.

171. Turner JA, Loeser JD, Bell KG. Spinal cord stimulation for chronic low back pain. A systematic literature synthesis. Neurosurgery 1995; 37:1088-1098.

172. Weinstein JN. The tortoise and the hare. Is there a place in spine surgery for randomized trials? Spine 1999; 23:2548-2549.

173. Winter RB. The prospective, randomized, controlled clinical trial in spine surgery. Fact or fiction? Spine 1999; 23:2550-2552.

174. Fairbank J. Randomized controlled trials in the surgical management of spinal problems. Spine 1999; 23:2556-2563.

175. Tosteson TD. Point of view. Spine 1999; 24:25622563.

176. Concato J, Shah N, Horwitz R. Randomized, controlled trials, observational studies, and the hierarchy of research designs. N Engl J Med 2000; 342:18871892.

177. Pocock S, Elbourne D. Randomized trials or observational tribulations? (editorial) N Engl J Med 2000; 342:1907-1909.

178. Fowler FJ. Using patient reports to evaluate medical outcomes. United States Congress, Office of Technology Assessment. Tools for Evaluating Health Technologies. Five Background Paper, BP-H-142. Washington, DC, U.S. Government Printing Office, February, 1995.

179. Cicala RS, Wright H. Outpatient treatment of patients with chronic pain. Analysis of cost savings. Clin J Pain 1989;5:223-226.

180. Hopwood M. Outcomes assessment in pain management. In Abram SE (ed). Pain Management. Philadelphia, Churchill-Livingston, 1998, pp 14.1-14.11.

181. Piccirillo JF. Outcomes research and otolaryngology. Otolaryngol Head Neck Surg 1994; 111:764-769.

182. Ross Davies A, Doyle AT, Lansky D et al. Outcomes assessment in clinical settings: A consensus statement on principles and best practices in project management. Joint Commission Journal on Quality Improvement 1994; 20:6-16.

183. The Foundation for Health Services Research. Health Outcomes Research Primer. Washington, DC, The Foundation for Health Services Research, 1994.

184. Epstein RS, Sherwood LM. From outcomes research to disease management: A guide for the perplexed. Ann Intern Med 1996; 124:832-837.

185. Greenfield S, Kaplan SH, Silliman RA et al. The uses of outcomes research for medical effectiveness, quality of care, and reimbursement in Type II diabetes. Diabetes Care 1994; 17:32-39.

186. Lynn J, Virnig BA. Assessing the significance of treatment effects: Comments from the perspective of ethics. Med Care 1995; 33:AS292-AS298. 
187. Wilson IB, Kaplan S. Clinical practice and patient health status: How are the two related? Med Care 1995; 33:AS209-AS214.

188. Guo HR, Tanaka S, Halperin WE et al. Back pain prevalence in US industry and estimates of lost work days. Am J Public Health 1999; 89:1029-1035.

189. Malter AD, Larwon EB, Urban N et al. Cost-effectiveness of lumbar discectomy for the treatment of herniated intervertebral disc. Spine 1996;21:1048-1055.

190. Mueller-Schwef EG, Hassenbusch SJ, Reig E. Costeffectiveness of intrathecal therapy for pain. Neuromodulation 1999; 2:77-84.

191. Abram SE, O'Connor TC. Complications associated with epidural steroid injections. Reg Anesth 1996;212:149-162.

192. Nelson DA. Intraspinal therapy using methylprednisolone acetate. Spine 1993;18:278-286.

193. Manchikanti L. The value and safety of steroids in neural blockade, part I. AJPM 2000; 10:74-83.

194. Manchikanti, L. The value and safety of steroids in neural blockade, part II. AJPM 2000; 10:122-134.

195. Manchikanti L, Pampati V, Beyer C et al. The effect of neuraxial corticosteroids on weight and bone mass density: A prospective evaluation. Pain Physician 2000; 3: 357-366.

196. Hopwood MB, Abram SE. Factors associated with failure of lumbar epidural steroids. Reg Anesth 1993; 18:238-243.

197. Sandrock NJG, Warfield CA. Epidural steroids and facet injections. In Warfield CA (ed). Principles and Practice of Pain Management. New York, McGrawHill, 1993, pp 401-412.

198. Schwarzer AC, Aprill CN, Derby R et al. The relative contributions of the disc and zygapophyseal joint in chronic low back pain. Spine 1994;19:801-806.

199. Kellgren JH. The anatomical source of back pain. Rheumatol Rehab 1977; 16:3-12.

200. Hirsch D, Inglemark B, Miller M. The anatomical basis for low back pain. Acta Orthop Scand 1963;33:1.

201. Thelander U. Fagerlung M., Friberg S et al. Straight leg raising test vs radiologic size, shape, and position of lumbar disc herniations. Spine 1992;17:395-389.

202. Deyo RA, Rainville J, Kent DL. What can the history and physical examination tell us about low back pain? JAMA 1992; 268:760-765.

203. Waddell G, Turk DC. Clinical assessment of low back pain. In Turk DC, Melzack R (eds). Handbook of Pain Assessment, ed 1. New York, The Guilford Press, 1992, pp 15-36.

204. Haldeman S. Failure of the pathological model to predict back pain. Spine 1990; 15:718-732.

205. Manchikanti L, Pampati V, Fellows B et al. The inability of the clinical picture to characterize pain from facet joints. Pain Physician 2000; 3:158-166.

206. Fortin J. Precision diagnostic disc injections. Pain Physician 2000; 3:271-288.
207. Bogduk N. International spinal injection society guidelines for the performance of spinal injection procedures. Part 1. Zygapophyseal joint blocks. Clin J Pain 1997; 13:285-302.

208. Manchikanti L, Pampati VS, Pakanati RR et al. Prevalence of facet joint pain in chronic low back pain. Pain Physician 1999; 2:59-64.

209. Manchikanti L, Pampati RR, Fellows B et al. The diagnostic validity and therapeutic value of medial branch blocks with or without adjuvants. Current Review of Pain 2000; in press.

210. Schwarzer AC, Derby R, Aprill CN et al. The value of the provocation response in lumbar zygapophysial joint injections. Clin J Pain 1994; 10:309-313.

211. Schwarzer AC, Aprill CN, Derby R et al. Clinical features of patients with pain stemming from the lumbar zygapophysial joints. Is the lumbar facet syndrome a clinical entity? Spine 1994; 19:1132-1137.

212. Manchikanti L. Facet joint pain and the role of neural blockade in its management. Current Review of Pain 1999; 3:348-358.

213. Dreyfuss PH, Dreyer SJ, Herring SA. Contemporary concepts in spine care. Lumbar zygapophysial (facet) joint injections. Spine 1995; 20:2040-2047.

214. Schwarzer AC, Wang SC, O'Driscoll D et al. The ability of computed tomography to identify a painful zygapophysial joint in patients with chronic low back pain. Spine 1995; 20:907-912.

215. Hendler NH, Bergson C, Morrison C. Overlooked physical diagnoses in chronic pain patients involved in litigation. Part 2. Psychosomatics 1996; 37:509517.

216. Hendler NH, Kolodny AL. Using medication wisely in chronic pain. Patient Care 1992; May 15: 125.

217. Waddel G, McCulloch JA, Kummel E et al. Nonorganic physical signs in low back pain. Spine 1980; 5:117-125.

218. Waddell G, Main CJ, Morris EW et al. Chronic lowback pain, psychological distress, and illness behavioor. Spine 1984; 9:209-213.

219. Main CJ, Waddell G. Behavioral responses to examination. A reappraisal of the interpretation of "nonorganic signs." Spine 1998; 23:2367-2371.

220. Maruta T, Goldman S, Chan CW et al. Waddell's Nonorganic Signs and Minnesota Multiphasic Personality Inventory Profiles in Patients with Chronic Back Pain. Spine 1977; 22:72-75.

221. Wallis BJ, Lord SM, Bogduk N. Resolution of psychological distress of whiplash patients following treatment by radiofrequency neurotomy. A randomized, double-blind, placebo-controlled trial. Pain 1997; 73:15-22.

222. Derby R, Bogduk N, Kine G. Precision percutaneous blocking procedures for localizing spinal pain. Part 2. The lumbar neuraxial compartment. Pain Digest 1993; 3:175-188. 
223. Woodward JL, Herring SA, Windsor RE. Epidural procedures in spine pain management. In Leonard TA (ed). Pain Procedures in Clinical Practice, ed 2. Philadelphia, Hanley and Belfus, 2000, pp 341-376.

224. O'Neill C, Derby R. Precision injection techniques for diagnosis and treatment of lumbar disc disease. ISIS Scientific Newsletter 1999; 3 34-58.

225. Manchikanti L. CPT 2000: Interventional pain management coding in the new millennium. Pain Physician 2000; 3:73-85.

226. Furman M. Is it really possible to do a selective nerve root block? ISIS Scientific Newsletter 1999; 3:3.

228. Siddle P Cousins M. Spinal pain mechanisms. Spine 1997; 22:98-104.
229. North RB, Kidd DH, Zahurak M et al. Specificity of diagnostic nerve blocks: A prospective, randomized study of sciatica due to lumbosacral spine disease. Pain 1996; 65:77-85.

230. Carrette S, Marcoux S, Leclaire R. Corticosteroid injections for sciatica. N Engl J Med 1997;337:12411243.

231. Koes BW, Bourer LM, Beckerman H et al. Physiotherapy exercises and back pain - A blinded review. Br Med J 1991; 302, 1572-1576. 